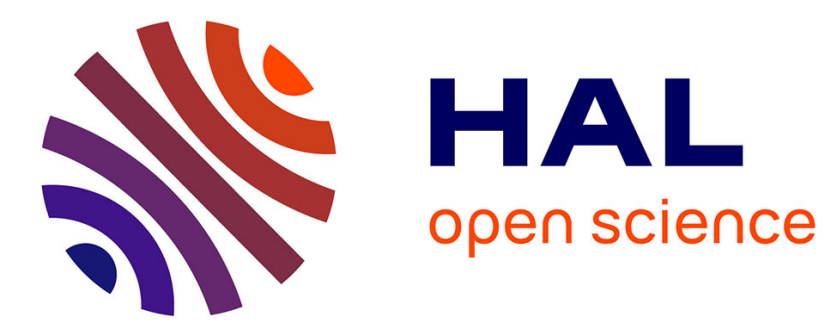

\title{
Gas storage
}

Deneb Peredo-Mancilla, Imen Ghouma, Cecile Hort, David Bessieres, Camélia

Matei Ghimbeu

\section{To cite this version:}

Deneb Peredo-Mancilla, Imen Ghouma, Cecile Hort, David Bessieres, Camélia Matei Ghimbeu. Gas storage. Mejdi Jeguirim; Lionel Limousy. Char and Carbon Materials Derived from Biomass. Production, Characterization and Applications, Elsevier, pp.341-382, 2019, 978-0-12-8148938. 10.1016/B978-0-12-814893-8.00009-2 . hal-02464977

\section{HAL Id: hal-02464977 https://hal.science/hal-02464977}

Submitted on 4 Feb 2020

HAL is a multi-disciplinary open access archive for the deposit and dissemination of scientific research documents, whether they are published or not. The documents may come from teaching and research institutions in France or abroad, or from public or private research centers.
L'archive ouverte pluridisciplinaire HAL, est destinée au dépôt et à la diffusion de documents scientifiques de niveau recherche, publiés ou non, émanant des établissements d'enseignement et de recherche français ou étrangers, des laboratoires publics ou privés. 


\title{
Chapter 9: Gas Storage
}

Deneb Peredo-Mancilla ${ }^{\mathrm{a}, \mathrm{c}}$, Imen Ghouma ${ }^{\mathrm{b}}$, Cecile Hort ${ }^{\mathrm{c}}$, David Bessieres ${ }^{\mathrm{a}}$, Camélia Matei

\author{
Ghimbeu, ${ }^{\text {,* }}$
}

${ }^{a}$ CNRS/Total/Univ Pau \& Pays Adour/ E2S UPPA, Laboratoire des Fluides Complexes et Leurs Reservoirs-IPRA, UMRS5150, 64000, Pau, Fr.

bInstitut de Sciences des Matériaux de Mulhouse, CNRS UMR 7361-UHA, 15 rue Jean Starcky, 68057 Mulhouse, Fr.

'Univ Pau \& Pays Adour/ E2S UPPA, Laboratoire de Thermique,

Energetique et Procédés-IPRA, EA1932, 64000, Pau, Fr.

*camelia.ghimbeu@uha.fr

\section{ABSTRACT}

The continuous increase of energy demands based on fossil fuels in the last years have lead to an increase of greenhouse gases (GHG) emission which strongly contribute to global warming. The main strategies to limit this phenomenon are related to the efficient capture of these gases and to the development of renewable energies sources with limited environmental impact. Particularly, carbon dioxide $\left(\mathrm{CO}_{2}\right)$ and methane $\left(\mathrm{CH}_{4}\right)$ are the main constituents of greenhouse gases while hydrogen $\left(\mathrm{H}_{2}\right)$ is considered an alternative clean energy source to fossil fuels. Therefore, tremendous research to store these gases has been reported by several approaches and among them the physisorption on activated carbons (AC) have received significant attention. Their abundance, low cost and tunable porous structure and chemical functionalities with an existing wide range of precursors that includes bio-wastes make them ideal candidates for gas applications. This chapter presents the recent developments on $\mathrm{CH}_{4}, \mathrm{CO}_{2}$ and $\mathrm{H}_{2}$ storage by activated carbons with focus on biomass as precursor materials. An analysis of the main carbon properties affecting the AC's adsorption capacity (i.e. specific surface area, pore size and surface chemistry) is discussed in detail herein.

Key words: Gas storage; activated carbons; biomass; methane; carbon dioxide; hydrogen; 


\section{Table of contents}

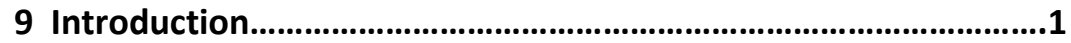

9.1 Methane Storage

$9.2 \mathrm{CO}_{2}$ Storage

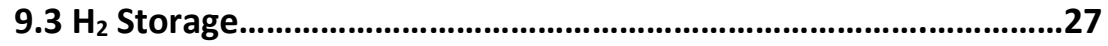

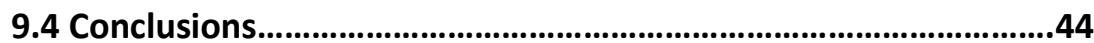

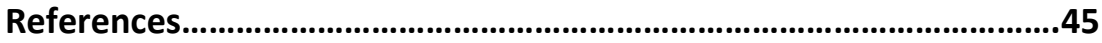




\section{Introduction}

Gases play an important role in our daily life. They are usually found in the form of gas mixtures with the one most known being atmospheric air which is constitute of approximate volumes of $78.08 \%$ nitrogen $\left(\mathrm{N}_{2}\right), 20.95 \%$ oxygen $\left(\mathrm{O}_{2}\right), 0.93 \%$ argon $(\mathrm{Ar}), 0.03 \%$ carbon dioxide $\left(\mathrm{CO}_{2}\right)$ and traces of methane $\mathrm{CH}_{4}$, helium (He), neon ( $\left.\mathrm{Ne}\right)$, krypton ( $\left.\mathrm{Kr}\right)$, xenon (Xe) and ozone $\left(\mathrm{O}_{3}\right)($ Encyclopedia Britannica, 2018). Amongst them, $\mathrm{CO}_{2}, \mathrm{CH}_{4}$ and nitrogen oxides $\left(\mathrm{NO}_{\mathrm{x}}\right)$ are a product of incomplete burning of fossil fuels (coal, oil, diesel, natural gas) and are the major contributors of global warming (GW) as they are emitted in higher amounts than other greenhouse gases (GHG) such as hydrofluorocarbons (HFCs), perfluorocarbons (PFCs) and hexafluorocarbon $\left(\mathrm{F}_{6} \mathrm{C}\right)$.As it can be seen in Figure 1, the atmospheric concentrations of these three gases have dramatically increases since the pre-industrial years $(\approx 1850)$ thus the reduction of their emissions has become a main target arising a need for new technologies for the selective adsorption and storage of these pollutants (Core Writing Team et al., 2014).

Carbon dioxide is a major compound in the gaseous effluent of many industrial processes, the fossil fuel power plants being the most important source $\left(40 \%\right.$ of the total $\left.\mathrm{CO}_{2}\right)$. In order to reduce its emission, the main issues include increasing the power plants efficiency, , the change towards nuclear and renewable energies and the implementation of carbon capture and storage (CCS) systems (Alonso et al., 2017). CCS can be used as a promising strategy to reduce not only the power plants emissions but it can also be employed in many industrial sectors such as the petrochemical industry, iron and steel refineries and cement production.

There are many separation technologies available for the separation and storage of $\mathrm{CO}_{2}$ : amine scrubbing, water scrubbing, membranes separation, cryogenic separation, biological and physical adsorption. Most of the commercial CCS systems use amine or water scrubbing but they have important drawbacks such as production of undesirable by-products, high energy regeneration, high corrosion and low cost efficiency. In this context, physical adsorption has the advantages of having low 
energy requirements, cost advantage, no use of water or additional chemicals and being easy to scale to a wide range of temperatures and pressures (Ben-Mansour et al., 2016).

For the case of methane, the principal anthropogenic sources are thought to be the production of livestock, natural gas production and distribution, emissions from landfills and the coal mining (Alonso et al., 2017). Due to methane's low volumetric energy density, its storage in order to use as a clean energy source involves the use of high pressures to obtain compressed natural gas (CNG) and low temperatures, down to $120 \mathrm{~K}$, for liquefied natural gas (LNG). These methods have a very high energy output as well as various security issues that limit their use. The storage of methane by adsorption in a solid material, known as adsorbed natural gas (ANG) presents advantages over LNG and CNG in terms of energy efficiency and safety. An ANG storage system would have the ability of storing great quantities of methane in small volumes under atmospheric conditions. To compete with other fuels (and other methane storage forms), the department of energy (DOE) of the U.S. has established a $\mathrm{CH}_{4}$ storage capacity of $180 \mathrm{v} / \mathrm{v}$ (volume of gas adsorbed at standard temperature and pressure: $298 \mathrm{~K}, 0.1$ MPa per volume of the storage vessel)(Choi et al., 2016; Ma et al., 2008).

In order to mitigate climate change a number of strategies are being implemented in addition to $\mathrm{CO}_{2}$ emission reduction and the use of methane as a clean energy source. Hydrogen $\mathrm{H}_{2}$ has a heating value three times higher than oil and its use as an energy results is completely free of pollution making it one of the most promising alternatives to the burning of fossil fuels. Unfortunately, similar to methane, the transportation and storage of hydrogen have proven to be a very challenging task. In order to be liquefied, it needs to be compressed below $33.2 \mathrm{~K}\left(\mathrm{H}_{2}\right.$ critical temperature)in a high energy demand process, and even when the compression process can be carried out the storage capacity of hydrogen is as low as $2 \mathrm{wt} . \%$ even at high pressures (20 MPa). A $\mathrm{H}_{2}$ storage target for use on vehicles of 5.5 wt.\%/40 g L ${ }^{-1}$ by 2017 and 7.5 wt.\%/70 g L-1 ultimate was established by the DOE(Office of Energy Efficiency \& Renewable Energy, n.d.). Aiming at this target the storage of hydrogen using porous materials is one of the most promising techniques (Liu et al., 2016). 
The development of porous adsorbent materials compatible with the adsorption of gases such as $\mathrm{CH}_{4}$, $\mathrm{CO}_{2}$ and $\mathrm{H}_{2}$ has become then a target issue for researchers, with the goals of finding cheap and ecofriendly precursor materials and implementing the synthesis procedures that will produce better yielding and the required properties of the material. There are a variety of porous materials used for the adsorption of gases such as zeolites (Cavenati et al., 2004; Chen and Ahn, 2014; Kacem et al., 2015), carbon nanotubes (Gui et al., 2013; Lee et al., 2006), metal organic frameworks (MOFs) (Casco et al., 2015a; Llewellyn et al., 2008; Zhou et al., 2007) and activated carbons(Buss, 1995; Byamba-Ochir et al., 2017; Munusamy et al., 2015). Among these materials, activated carbons are the most widely used in the industry, due to their ease of synthesis as well as the possibility of their pore tailoring and chemical functionalization. In addition, activated carbons can be produced from biomass as the carbon source with the advantages of low cost, high availability, valorization of agricultural wastes and development of high specific surface area adsorbent (Feroldi et al., 2018).

In this chapter, the use of activated carbons for the adsorption of key gases with a focus on biomassderived activated carbons is discussed. A particular attention is paid on the effect of the textural (like surface area and pore volume) and chemical properties (surface groups) upon the activated carbons adsorption behavior. .

\subsection{Methane Storage}

Methane $\left(\mathrm{CH}_{4}\right)$ accounts for about $10 \%$ of the total greenhouse gases emissions. Over $60 \%$ of total $\mathrm{CH}_{4}$ is generated by human activities such as energy production and, organic waste and the raising of livestock while the other $40 \%$ is emitted by natural sources like natural wetlands (EEA, 2014; EPA, 2016). As part of the global efforts to mitigate its environmental impact, methane is considered as a clean energy in the forms of natural gas and biomethane. The global increase of the main greenhouse gases from 1750 to 2011is shown in Figure 1. 


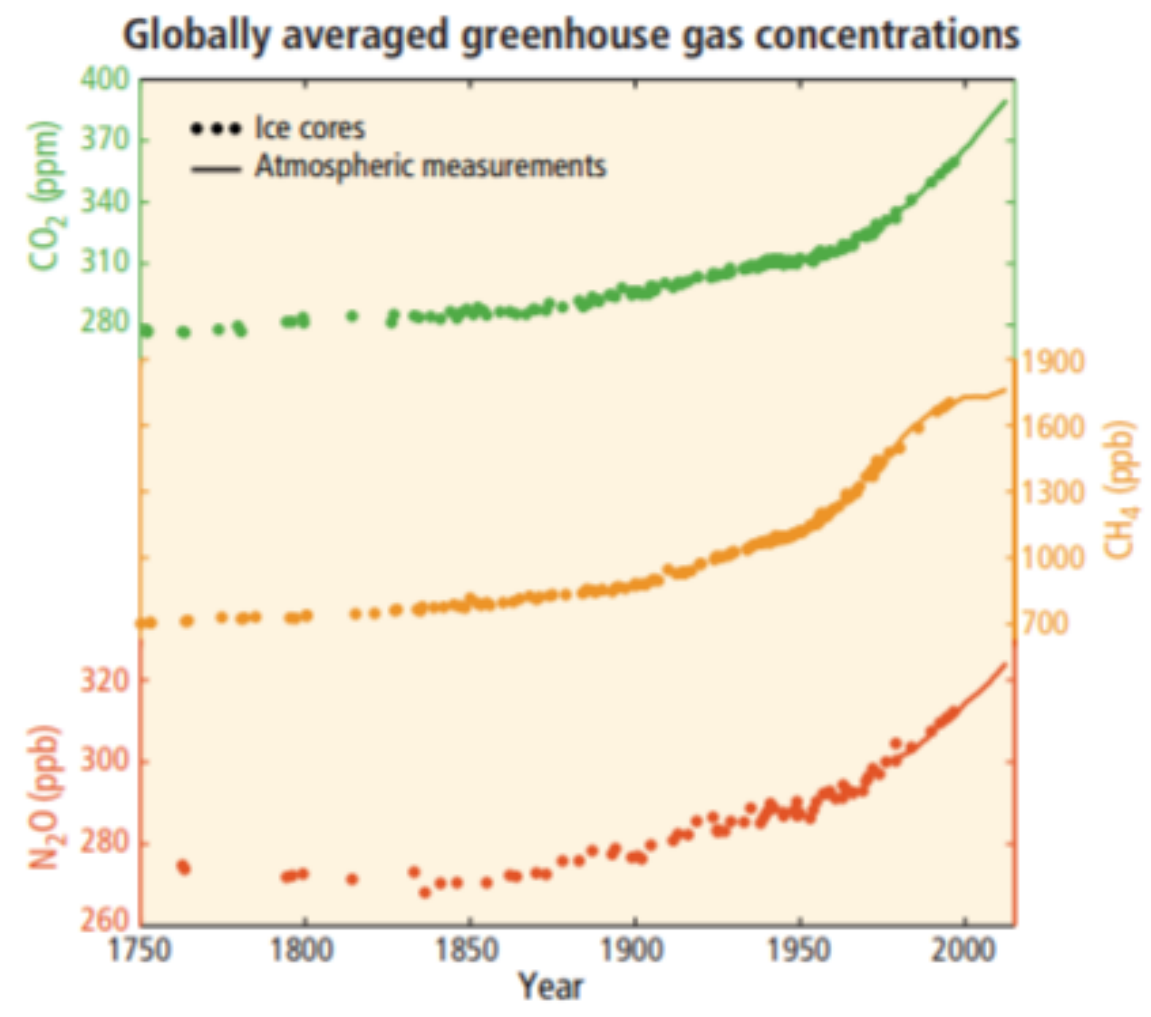

Fig. 1 Observed changes in atmospheric greenhouse gas concentrations between the years 1750 to 2011. Atmospheric concentrations of carbon dioxide $\left(\mathrm{CO}_{2}\right.$, green), methane $\left(\mathrm{CH}_{4}\right.$, orange) and nitrous oxide $\left(\mathrm{N}_{2} \mathrm{O}\right.$, red). Data from ice cores (symbols) and direct atmospheric measurements (lines) are overlaid . Reprinted from (Core Writing Team et al., 2014).

Natural gas is considered an alternative fuel due to its environmental benefits; its combustion is relatively cleaner than that of other fossil fuels. Natural gas use results in the production and emission of less pollutants, $29 \%$ less carbon dioxide per joule delivered than oil and $44 \%$ less than coal (NaturalGas.org, n.d.). As a vehicle fuel, methane emits 15 to 20 percent less greenhouse gases (GHG) than gasoline. The main component of natural gas is methane (approximately $90 \%$ and higher in most cases, it also contains a small portion of heavier hydrocarbons such as ethane $\left(\mathrm{C}_{2} \mathrm{H}_{6}\right)$, propane $\left(\mathrm{C}_{3} \mathrm{H}_{8}\right)$ and butane $\left(\mathrm{C}_{4} \mathrm{H}_{10}\right)$. On the other hand, biogas is the product of the anaerobic fermentation of organic matter which main constitutes are $\mathrm{CH}_{4}(50-75 \%)$ and $\mathrm{CO}_{2}$ (25-45\%) (see table 1). Biogas can be directly 
burned to generate electricity in a combined heat and power plant (CHP) or alternatively it can be purified to produce biomethane $\left(96 \% \mathrm{CH}_{4}\right)$ (Feroldi et al., 2018).

Table 1. Composition of natural gas and biogas in volume percentage (Feroldi et al., 2018).

\begin{tabular}{lll}
\hline Compound & Natural Gas & Biogas \\
& & \\
\hline Methane $\left(\mathrm{CH}_{4}\right)$ & $88.1 \%$ & $50-75 \%$ \\
Carbon dioxide $\left(\mathrm{CO}_{2}\right)$ & $0.8 \%$ & $25-45 \%$ \\
Ethane $\left(\mathrm{C}_{2} \mathrm{H}_{6}\right)$ & $4.2 \%$ & $*$ \\
Nitrogen $\left(\mathrm{N}_{2}\right)$ & $5.2 \%$ & $0-3 \%$ \\
Hydrogen $\left(\mathrm{H}_{2}\right)$ & $*$ & $0-2 \%$ \\
Hydrogen sulfide $\left(\mathrm{H}_{2} \mathrm{~S}\right)$ & $*$ & $\mathbf{0 - 1 \%}$ \\
\hline
\end{tabular}

* None detected

The utilization of biomethane as an alternative energy source also presents a variety of environmental benefits including decrease of greenhouse gas emissions, cheap organic waste recycling and the formation of nitrogen rich products that can be use as fertilizers. In addition, the similar properties of biomethane and methane make biomethane an alternative to replace or to be added to natural gas for vehicular engines. However, despite the benefits of using methane-rich fuels, their use is limited due to transportation and storage constraints. At normal temperature and pressure methane is in the gaseous state which results on a volumetric energy density of only $0.12 \%$ of that of gasoline. Table 2 shows the physical properties of methane.

Table 2. Physical Properties of methane (National Center for Biotechnology Information, n.d.). 


\begin{tabular}{lllll}
\hline Molar mass $\left(\mathrm{g} \mathrm{mol}^{-1}\right)$ & Boiling point (K) & Critical & Critical pressure & Critical density \\
& & temperature (K) & $(\mathrm{MPa})$ & $\left(\mathrm{g} \mathrm{cm}^{-3}\right)$ \\
& & & & \\
\hline 16.043 & 111.65 & 190.90 & 4.64 & 0.16 \\
\hline
\end{tabular}

Currently, $\mathrm{CH}_{4}$ storage methods are performed by means of compressed natural gas (CNG) or liquefied natural gas (LNG). These methods involve high cost processes (cryogenics and compression), special storage tanks. In addition, these methods present risks to safety due to the use of high pressure and/or the refueling of cryogenic liquids that complicate their use in the vehicle sector. A promising alternative that will reduce the costs and safety risks, consists in the storage of natural gas (or biomethane) at low pressure and normal temperature in the adsorbed form (ANG - adsorbed natural gas).

According to the US Department of Energy (DOE), in order to commercialize the ANG technology a target of $\mathrm{CH}_{4}$ storage capacity of $180 \mathrm{v} / \mathrm{v}$ at $35 \mathrm{MPa}$ (volume of gas at standard pressure and temperature conditions per volume of the storage vessel) was established (Burchell and Rogers, 2000). In this context, the search of efficient adsorbent materials that can meet the DOE standards has become a major challenge.

The established value of $180 \mathrm{v} / \mathrm{v}$ corresponds to the energy density of CNG at a pressure of $16.3 \mathrm{MPa}$ (Table 3). This value is considered as a reference target when searching for new adsorbents. However, the U.S. department of Energy under the program "Methane Opportunities for Vehicular Energy (MOVE)" demands an energy density for the ANG systems equivalent to CNG under $25 \mathrm{MPa}$ (266 v/v) (Energy, U.S. Department of Energy: Washington, 2012).

Table 3. Energy Densities of Methane and Conventional Fluids (Kumar et al., 2017a). 


\begin{tabular}{lll}
\hline Pressure (MPa) & Volumetric storage & Energy density (MJ/L) \\
& capacity (v/v) at STP & \\
& & \\
\hline CNG (15 MPa) & 168 & 5.80 \\
CNG (20 MPa) & 222 & 7.68 \\
CNG (25 MPa) & 266 & 9.2 \\
LNG (110 K and 0.1 MPa) & 600 & 22.2 \\
Gasoline & $*$ & 34.2 \\
Diesel & $* *$ & 37.3 \\
\hline
\end{tabular}

$1 \mathrm{~L}$ of $\mathrm{CH}_{4}=0.0345 \mathrm{MJ}$.

* Required density of methane in a CNG tank to make it equivalent to gasoline

${ }^{* *}$ Required density of methane in a CNG tank to make it equivalent to diesel: $1.0785 \mathrm{~g} / \mathrm{cm} 3$

It is of general consensus that an efficient adsorbent for the storage of methane must have a high specific surface area (from $1000 \mathrm{~m}^{2} / \mathrm{g}$ up to $3000 \mathrm{~m}^{2} / \mathrm{g}$ ), with a pore size distribution that ranges around 1.0 to $2.0 \mathrm{~nm}$ with a micropore volume of at least $85 \%$ of total pore volume (Biloe et al., 2001). Different class of porous materials has been studied aiming to reach the DOE target including activated carbons, ordered carbonaceous materials, zeolites and MOFs.

Among the available adsorbent materials, activated carbons present advantages that make them suitable materials for gas storage such as high surface area, large pore volume and light weight. In particular, for the methane storage process they have the benefits of not being sensitive to humid conditions, they tend to have reasonable prices as well as good adsorption properties at atmospheric pressure. 
The adsorption capacity of activated carbons (ACs) is highly related to the textural properties. They present a wide range of pore sizes that goes from the micropore to macropore region and a surface area between 400 and $3000 \mathrm{~m}^{2} \mathrm{~g}^{-1}$. Furthermore, their textural properties can be controlled by various activation factors.

The $\mathrm{CH}_{4}$ molecule is symmetrical and therefore it does not present a dipole or quadripole. It is difficult then, to increase the storage capacity of the adsorbent by surface modification. However, the gas storage capacity of ACs can be enhanced by controlling the pore structures. For the methane adsorption, it has been found that the presence of high microporosity with no macropore volume is optimal since the size of the methane molecules are equivalent to the size of micropore. An average pore volume of at least $0.8 \mathrm{~nm}$ (diameter greater than two molecules of methane) is wished (Antoniou et al., 2014; Cracknell et al., 1993). In fact, since the interaction of the methane molecules with activated carbons is governed by van der Waals interactions, the attractive force of the pore walls of the adsorbent are a function of the distance $z$ between the center of the methane molecule and the center of a carbon atom on the pore wall, this interaction can be described by the Lennar-Jones

potential (Fig. 2).

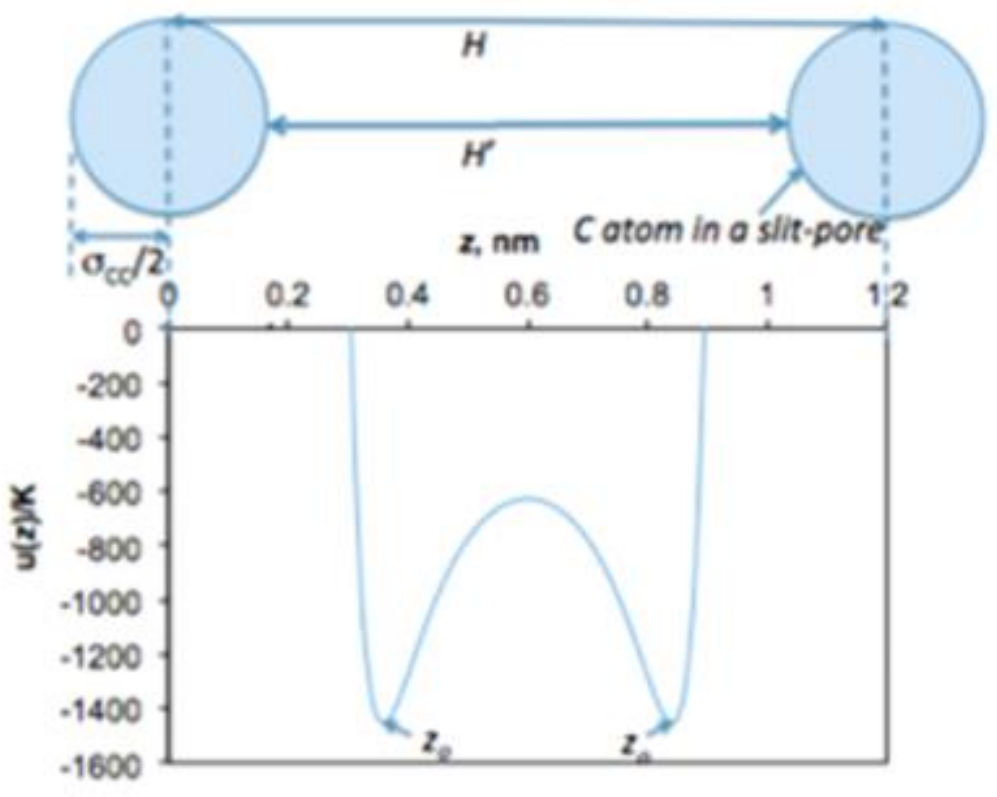

Fig.2 Potential energy, $u(z)$, for a spherical methane Lennard-Jones (L) site interacting with walls of a slit pore of width $H=1.2 \mathrm{~nm}$ in terms of the distance $z$ ( distance between the center of the methane 
molecule and the center of a wall carbon atom). Reprinted with permission from(Kumar et al., 2017a). Copyright 2017 American Chemical Society.

The attraction force becomes stronger when $z$ is equivalent to one methane molecular diameter ( 0.36 $\mathrm{nm})$, at longer distances the attraction energy becomes too week and thus the formation of a second adsorbed layer is impeded, the rest of the methane molecules will filled the empty pore space with a low gas-like density.

A linear relationship between the micropore volume (up to $1.6 \mathrm{~cm}^{3} \mathrm{~g}^{-1}$ ) and the methane adsorption capacity of different activated carbons at 35 bars and 298 K Fig. 3) could be established. However, a large portion of pores that have an optimal size of around $0.8 \mathrm{~nm}$ plays a major role in the adsorption of methane (Lozano-Castelló et al., 2002).

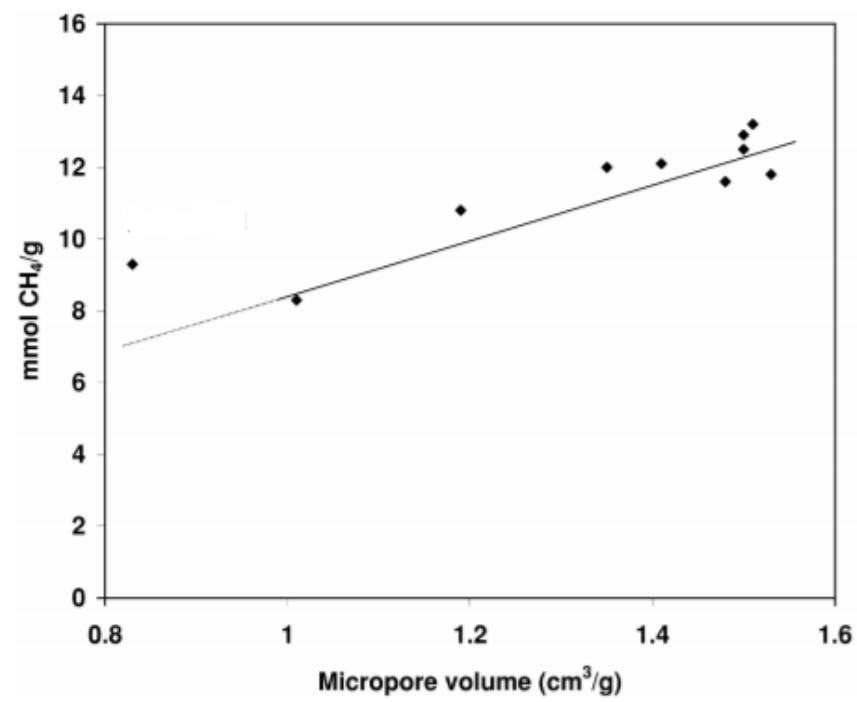

Fig.3 Relationship of the methane adsorption capacity at 35 bar and $298 \mathrm{~K}$ with the micropore volume for a series of activated carbons calculated by $\mathrm{N}_{2}$ adsorption isotherms. Reprinted from (LozanoCastelló et al., 2002) with permission from Elsevier.

Furthermore, it has been reported that the presence of pores larger than $0.8 \mathrm{~nm}$ is needed in order to facilitate the access and adsorption of the gas molecules. For example, García-Blanco et al. showed that the Maxorb activated carbon, with a surface area of $3090 \mathrm{~m}^{2} \mathrm{~g}^{-1}$ and a pore size distribution from 
pores between 0.5 and $3 \mathrm{~nm}$ showed a micropore filling of only $59 \%$ when adsorbing methane at 298 $\mathrm{K}$ and $3500 \mathrm{kPa}$. However, even if the micropore filling was low, the narrow micropore $(<0.8 \mathrm{~nm})$ filling is total, indicating that methane is not only adsorbed in the narrow micropores but also of pores of larger size (García Blanco et al., 2016).

This need of larger pores for the methane adsorption was also evidenced by Casco et al. when comparing a set of activated carbons with different pore volumes (Fig .4) (Casco et al., 2015b). Samples with pure micropororous network (F400 and Maxsorb) showed a maximum adsorption capacity at moderate working pressures $(6-8 \mathrm{MPa}) . \mathrm{In}$ contrary, samples that combine micropores with mesopores (pore size $<2 \mathrm{~nm}$ ) such as the activated carbons RGC30, LMA738, LMA405 and LMA726, there was a continuous increase of the adsorbed quantity. Furthermore, they found that the correct design of activated carbons can result in materials that meet both the DOE and DOE MOVE requirements set by the U.S. department of energy.

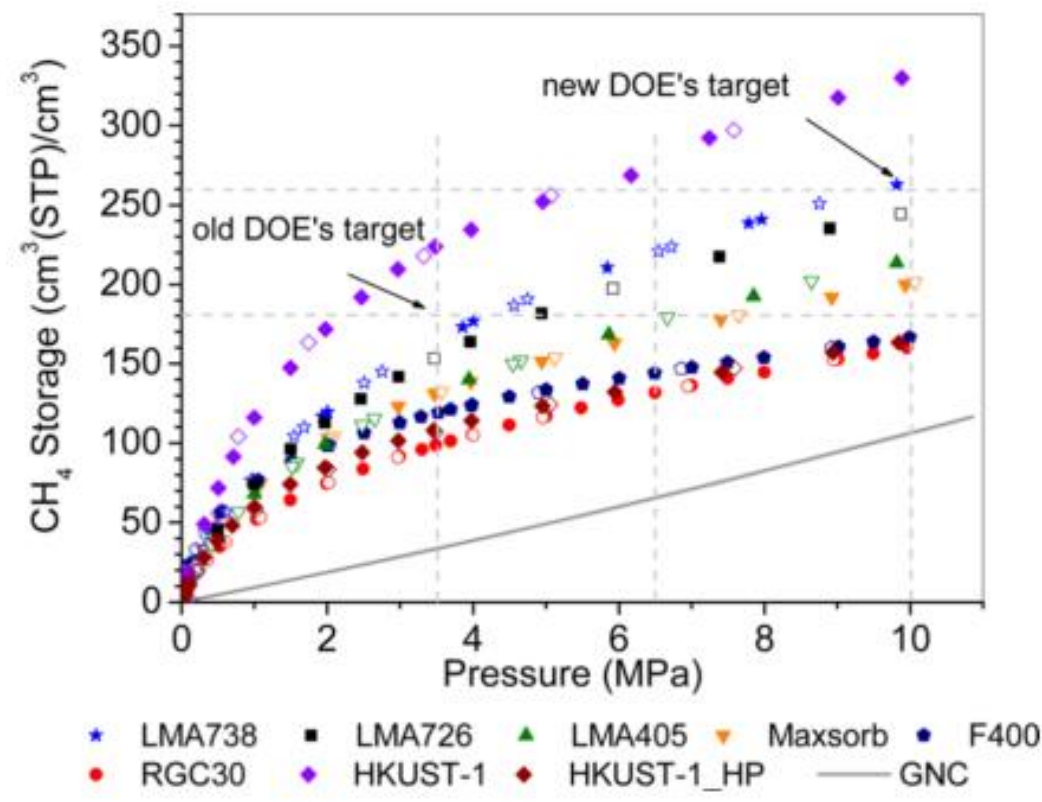

Fig. 4 Methane storage capacity for different activated carbons at $298 \mathrm{~K}$ and up to $10 \mathrm{MPa}$. MOF sample HKUST-1 has been included for the sake of comparison (closed symbols represent adsorption data, open symbols represent desorption data).Reprinted with permission from(Casco et al., 2015b). Copyright 2015 American Chemical Society. 
As it was previously mentioned, the feasibility of using ANG instead of CNG and LNG relays on the ability of the adsorbent to store a high amount of gas inside the fuel tank, which means that the porous adsorbent must present a high packing density ensuring that the storage capacity and the energy density, on volumetric basis is high. Since the microporosity of ACs is created by removal of carbon atoms during the activation process, after a certain microporosity volume further activation is followed by the creation of macropores translating into a useless volume for gas storage and thus a decrease of the packing density. Hence, carbons with high $\mathrm{CH}_{4}$ uptake might result in a lower volumetric storage capacity of methane than some with lower surface area. In this sense, it is useful to express the adsorption capacities in terms of volumetric quantities instead of gravimetric basis (Fig. 5) (Menon and Komarneni, 1998).
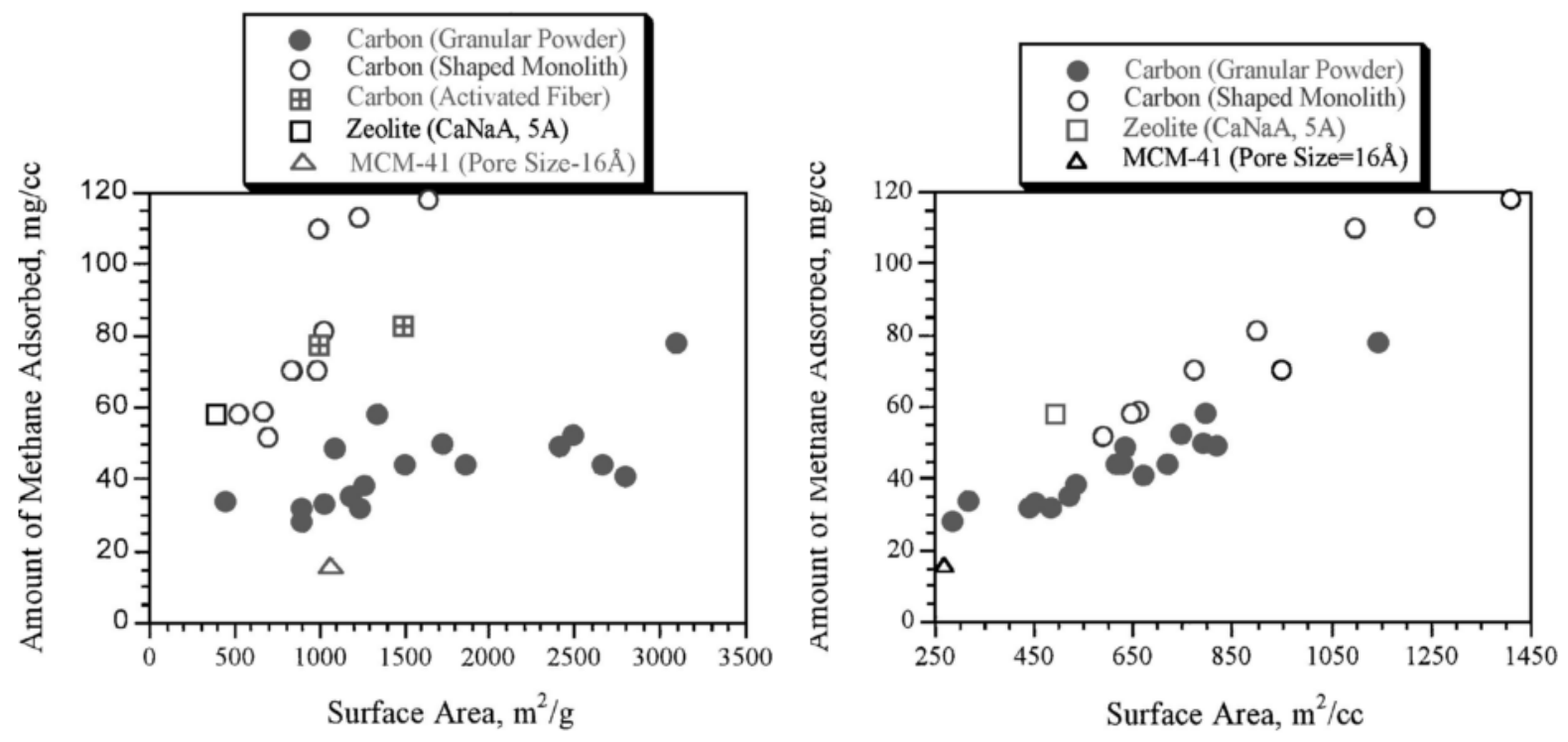

Fig 5. Effect of expressing the methane adsorption capacity in terms of gravimetric surface $\left(\mathrm{m}^{2} \mathrm{~g}^{-1}\right)$ area vs volumetric surface area $\left(\mathrm{m}^{2} \mathrm{~cm}^{-3}\right)$ for different porous materials at $3.447 \mathrm{MPa}$ and $298 \mathrm{~K}$. A suited adsorbent for the ANG storage presents a maximum volumetric surface area. Reprinted by permission from Springer (Menon and Komarneni, 1998). Copyrights 1988.

Along with a high micropore volume, the activated carbon is required to have a high packing density, thus presenting a high energy density on volumetric basis. Optimization of the packing density can be 
done by means of improving the bulk density, monolith preparation and particle size design. It is strongly related to the activation degree of the adsorbent, the higher the surface area and pore volume are the lower the packing density is. Byamba-Ochir et al. showed the importance of the activation conditions for the preparation of ACs for methane storage. Authors found that the BET surface area increased with an increase of the ratio of activating agent and the Mongolian raw anthracite, however, the packing density gradually decreases and therefore does the volumetric capacity (Table 3) (ByambaOchir et al., 2017).

Table 4. Effect of activating agent/Mongolian raw anthracite radio in the volumetric methane adsorption capacity (Byamba-Ochir et al., 2017)

\begin{tabular}{lll}
\hline Carbon monoliths & SBET $\left(\mathrm{m}^{2} / \mathrm{g}\right)$ & $\mathrm{v} / \mathrm{v}\left(\mathrm{cm}^{3} \mathrm{CH}_{4} / \mathrm{cm}^{3}\right.$ activated carbon $)$ \\
\hline PMAC2/1-C3-65 & 622 & 43.6 \\
PMAC1/1-C3-65 & 845 & 60.1 \\
PMAC1/2-C3-65 & 1460 & 162.2 \\
PMAC1/3-C3-65 & 1757 & 147.8 \\
\hline
\end{tabular}

To further investigate the effect of the adsorbent design parameters and the volumetric storage capacity, Kumar et al. plotted the volumetric adsorption capacity versus the product of the packing density (PD) and the specific surface area of the adsorbents (Fig. 6) finding a logarithmic relationship. They determined that in order to achieve the volumetric methane adsorption capacity of $180 \mathrm{v} / \mathrm{v}$, the adsorbents must have a surface area of $2463 \mathrm{~m}^{2} \mathrm{~cm}^{-3}$ and packing density of about $1.2 \mathrm{gcm}^{-3}$. This are just guidelines since consideration of pore volume and distribution must be made (Kumar et al., 2017b). 
One important advantage of using activated carbons as adsorbent materials for gas separation and storage is the possibility of using different organic materials rich in carbon contents as precursors with coal and wood being the most employed ones. However, in recent years there has being an increasing interest on the production of AC from agricultural wastes. The use of this type of materials as precursors can reduce the pressure on mines and forests while valorizing products that otherwise result in waste production with economic and environmental impacts (Mozammel et al., 2002).

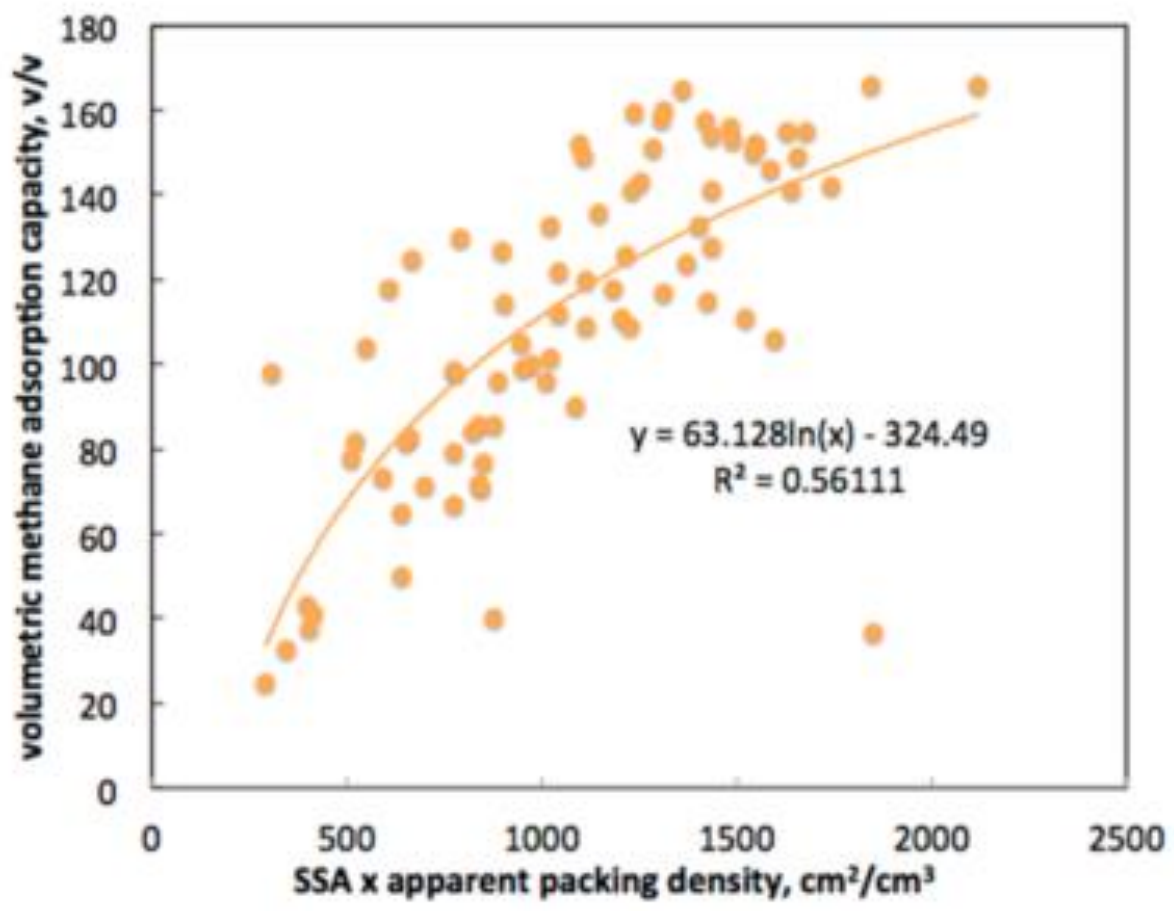

Fig. 6 Volumetric adsorption capacity (v/v) of carbon structures versus the product of the BET specific surface area (SSA) and packing density. Reprinted with permission from (Kumar et al., 2017a). Copyright 2017 American Chemical Society.

Examples of such precursor materials include rubber seed coat, olive seed, coconut shell, oil pal fiber and almond shell (Arami-Niya et al., 2012). Some of the results obtained using low-cost lignocellulosic biomass activated carbons for methane adsorption and storage are described in table 4 .

Table 5. Biowaste precursors used to prepare activated carbons along with their specific surface area and $\mathrm{CH}_{4}$ storage (González-García, 2018). 


\begin{tabular}{llll}
\hline Precursors & Activating Agent & Surface Area $\left(\mathrm{m}^{2} \mathrm{~g}\right)$ & Storage Capacity \\
\hline Sugarcane molasses & $\mathrm{KOH}$ & 2202 & $197.23 \mathrm{mg} \mathrm{g}^{-1}$ \\
Oil palm Shell & $\mathrm{ZnCl}_{2}$ & 870 & $13 \mathrm{~cm}^{3} \mathrm{~g}^{-1}$ \\
Corncob & $\mathrm{KOH}$ & 3227 & $273.4 \mathrm{~cm}^{3} \mathrm{~g}^{-1}$ \\
Corn cobs & $\mathrm{KOH}$ & 1320 & $120 \mathrm{v}^{\mathrm{v}}$ \\
Palm shell & $\mathrm{H}$ & $25.7 \mathrm{~cm}^{3} \mathrm{~g}^{-1}$ \\
Olive stones & $\mathrm{H}_{3} \mathrm{PO}_{4}$ & $4.69 \mathrm{mmol} \mathrm{g}^{-1}$ \\
& $\mathrm{H}_{3} \mathrm{PO}_{4}$ & 1014 & \\
\hline
\end{tabular}

$\overline{\text { Activated carbons can be optimized for methane storage by testing several activation conditions, such }}$ as activation method, activation temperature, activation agent, activation agent to char ratio. Bagher and Abedi. studied the effect of activation conditions on a corn cobs based AC, showing that the methane adsorption capacity can be increased from a low $25 \mathrm{v} / \mathrm{v}$ to up to $120 \mathrm{v} / \mathrm{v}$ at $298 \mathrm{~K}$ and 3.44 MPa when using optimal activation conditions: activation temperature ok $823 \mathrm{~K}$ for 60 minutes and impregnation with $\mathrm{KOH} / \mathrm{char}$ on a 1:1 ratio (Bagheri and Abedi, 2011). Using a similar optimization process Policicchio et al. were able to obtain a $\mathrm{CH}_{4}$ adsorption capacity of $150 \mathrm{v} / \mathrm{v}$ at $298 \mathrm{~K}$ and $3.5 \mathrm{MPa}$ for a cellulose based AC (Policicchio et al., 2013). This optimization relays on the change of the textural parameters of the adsorbent (such as BET surface area and pore size distribution) upon different activation conditions. Ruiz et al. tested the effect of different activation temperatures, activation agent/precursor weight and inner flow gas on the pore size distribution (Fig. 7) (Ruiz et al., 2017). Overall the best methane storage capacities were found when the activation method produced samples with high BET surface area. In the case of physical activation methods, a higher activation degree resulted in a development of the porosity thus resulting in a higher surface area. In the case of chemical activation, a low activation temperature (between 700 and $800{ }^{\circ} \mathrm{C}$ ) and a higher activation ratio/precursor resulted in a higher narrow micropore $(<0.8 \mathrm{~nm})$ volume. 
All the hitherto present studies show that the new DOE MOVE requirements are difficult to achieve by activated carbons and its feasibility is questionable. Furthermore, using Monte Carlo simulations a maximum methane storage capacity of activated carbons has been predicted to be $209 \mathrm{v} / \mathrm{v}$ at $3.4 \mathrm{MPa}$ (Matranga et al., 1992). Thus, this result implies for researchers working in the design of new materials for the methane storage to reconsider this targets and/or changing the operating conditions (i.e. using higher pressures).

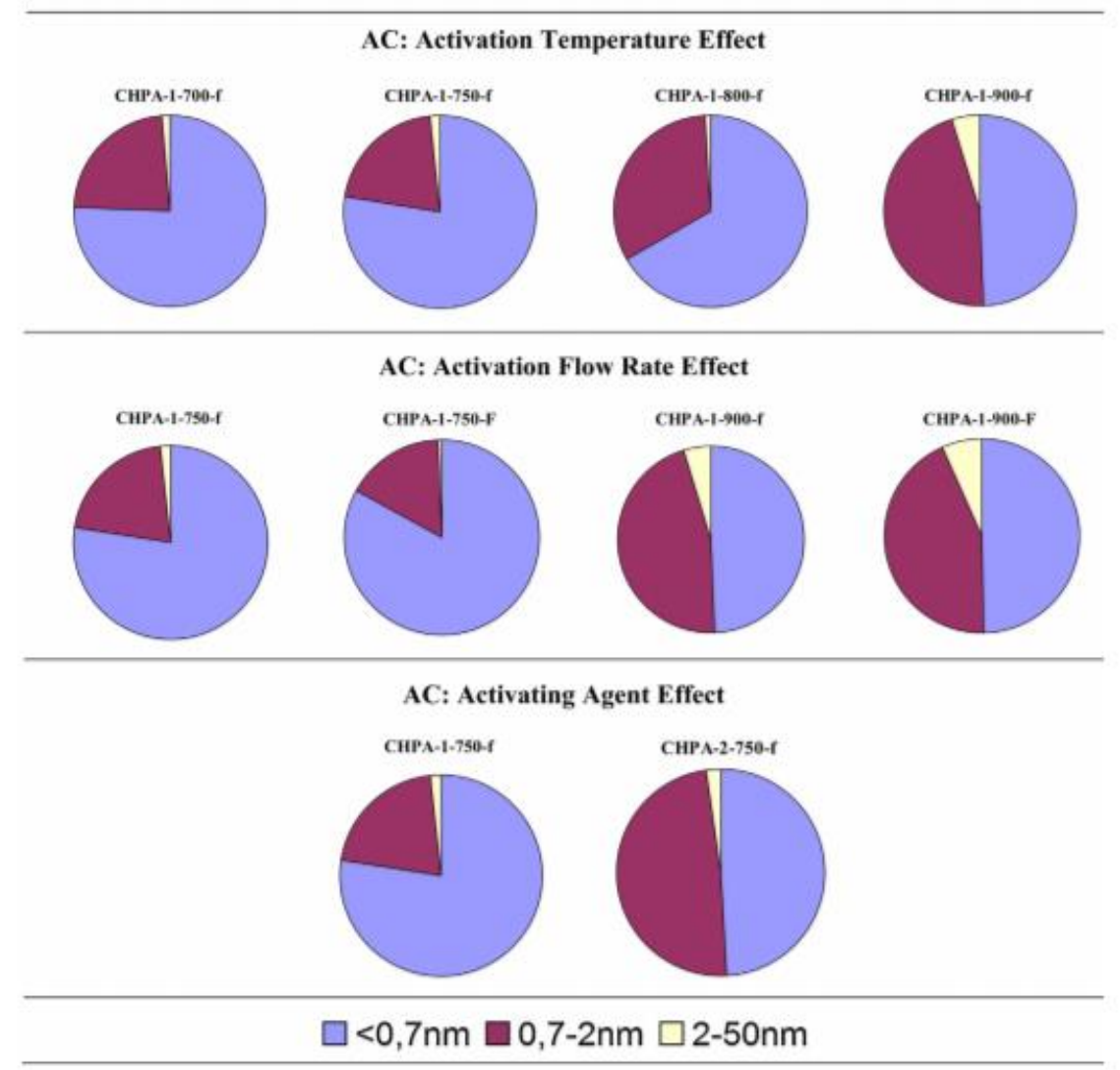

Fig. 7 Micro-mesoporosity volume distributions (in percentages) within the chestnut shell activated carbons. Reprinted from (Ruiz et al., 2017). Copyright ( 2017), with permission from Elsevier. 


\subsection{Carbon Dioxide Storage}

Reducing carbon dioxide $\left(\mathrm{CO}_{2}\right)$ emissions is a key factor to combat global warming since among the greenhouse gases $\mathrm{CO}_{2}$ is the one emitted in higher volume. It is estimated that in $2006, \mathrm{CO}_{2}$ alone accounted for $81.6 \%$ of the total GHG emissions in the US (United States Environmental Protection Agency (EPA), n.d.; Yamasaki, 2003). The $\mathrm{CO}_{2}$ atmospheric concentration has increased from a preindustrial value of $280 \mathrm{ppm}$ to $408 \mathrm{ppm}$ in 2018 resulting in an increase of $1^{\circ} \mathrm{C}$ of the global temperature (Intergovernmental Panel on Climate Change (IPCC), 2007; NASA, 2018).

The main source of carbon dioxide is the fossil fuels combustion followed by land-use change. Annual fossil fuels emissions increased from an average $6.4 \mathrm{GtC}$ in the $1990 \mathrm{~s}$ to $7.2 \mathrm{GtC}$ average per year in 2000-2005 (1 gigatonne of carbon or GtC = 1 billion tonnes of carbon) (Plaza et al., 2008). Fossil fuel combustion is the principal source of anthropogenic carbon dioxide emissions (58\% of global GHG emissions (International Energy Agency, 2017).

Carbon Capture and Storage (CCS) has been proposedas one of the most promising technologies to reduce carbon dioxide emissions in the short-term while carbon-free processes are implemented. It is believed that by the year 2050 CCS can reduce by $20 \%$ the carbon dioxide emissions (Global CCS Institue, 2011). CSS is a three step process:

i) Separation of $\mathrm{CO}_{2}$ from other emissions

ii) $\quad \mathrm{CO}_{2}$ transportation to the storage site

iii) Permanent storage

The transportation and the storage step are already developed technologies. It is the first stage of the CCS that has made difficult its implementation. The separation of the $\mathrm{CO}_{2}$ accounts for approximately two thirds of the total cost of a CCS (Intergovernmental Panel on Climate Change (IPCC), 2005; Li et al., 2011). In this sense, between the proposed carbon dioxide capture and separation options, post- 
combustion capture has been appointed as the most feasible to implement in power plants as it can be retrofitted to existing plants without modification of the already existing systems (Lee et al., 2012).

The process of post-combustion can be done by many separation technologies such as physical adsorption, chemical adsorption, cryogenic separation and membranes. Most of the carbon dioxide capture systems commercially available employ chemical absorption with alkaline amines. Despite of the method availability, remarkable disadvantages such as high energy requirements, oxidative degradation of the adsorbents, high corrosion and low cost efficiency are noted. Other possible technologies are cryogenic separation and membrane separation. However, the cryogenic separation has the disadvantage of using a great quantity of energy that makes it too expensive and the use of membranes is still in a very young developing phase (Oh, 2010).

Adsorption technology involves two steps, on the first step the carbon dioxide adsorption onto a porous adsorbent by the formation of chemical bonds (chemisorption) or by physical interactions such as van der Waals forces (physisorption). The second stage is the regeneration of the adsorption column after the system equilibration. The regeneration can be done by reducing the pressure (Pressure Swing Adsorption - PSA) or by increasing the temperature (Temperature Swing Adsorption - TSA).

The adsorption process using physisorbent materials is considered as the most cost-effective option for carbon dioxide separation due to its low energy requirements. In addition, it is a very noble technology that can be easily scale to different plant sizes and used on a wide range of temperatures and pressures. The success of an adsorption separation technology relays on the quality of the employed adsorbent. It has been described that a successful adsorbent for the carbon dioxide capture and storage should satisfy five main requirements (Sevilla et al., 2012):

i) Large $\mathrm{CO}_{2}$ uptake

ii) High sorption rate

iii) Good selectivity between $\mathrm{CO}_{2}$ and other competing gases

iv) Easy regeneration 
The search for new adsorbent materials that better fulfill these requirements has become an active field of research. Adsorbents that have been studied for this purpose include activated carbons, zeolites, MOFs and polymers.

It is important to mention here that development of better adsorbents for the carbon dioxide separation would not be only beneficial to the CCS systems but also for the upgrading of biogas and natural gas. In this context, activated carbons (CAs) are considered as a superior material for the $\mathrm{CO}_{2}$ capture and separation due to their hydrophobic character, lower cost, high thermal stability and low regeneration energy requirements (Plaza et al., 2010).

Similar to the adsorption process of methane, the textural properties of activated carbons play a major role on the adsorption behavior. $\mathrm{CO}_{2}$ adsorption is enhanced by the presence of micropores of up to 1 $\mathrm{nm}$. By comparing a number of porous carbons, Presser et al. showed that the volume of pores larger than $1 \mathrm{~nm}$ is not a major contributor to the $\mathrm{CO}_{2}$ adsorption (Fig. $8 \mathrm{c}$ ). In fact, it is the volume of ultramicropores (size smaller than $0.8 \mathrm{~nm}$ ) that has the higher influence upon $\mathrm{CO}_{2}$ adsorption as proven by a higher correlation coefficient ( $R^{2}$ of 0.9958$)$ (Fig. 8d). Presser et al. reported that upon very low $\mathrm{CO}_{2}$ partial pressures such as $0.01 \mathrm{MPa}$ it is the pores with a size smaller than $0.5 \mathrm{~nm}$ that are the main contributors (Presser et al., 2011). The dependency of the adsorption of carbon dioxide on the ultramicropore volume was also observed by Guojun et al. at 273, 283 and $293 \mathrm{~K}$ and pressures between $0.01 \mathrm{MPa}$ and 0.10 MPa (Yin et al., 2013).

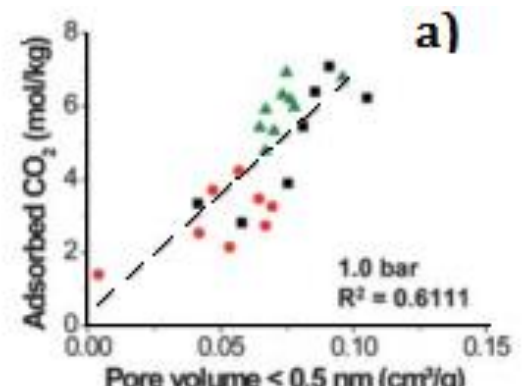

Pore volume $<0.5 \mathrm{~nm}\left(\mathrm{~cm}^{2} / \mathrm{g}\right)$

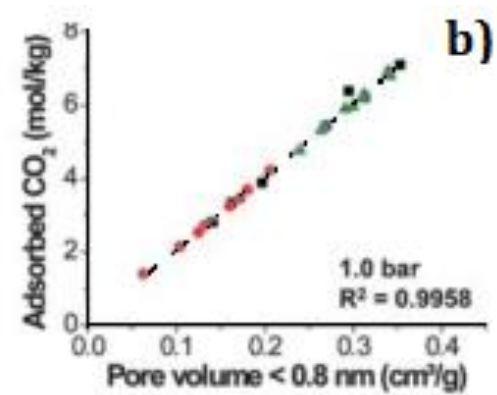

b)

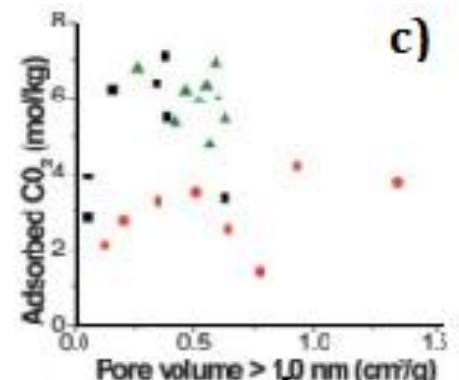


Fig. 8. $\mathrm{CO}_{2}$ uptake at $273 \mathrm{~K} 0.1 \mathrm{MPa}$ for the volume of pores a) Pore Volume $<0.5 \mathrm{~nm}$, b) ) Pore Volume $<0.8 \mathrm{~nm} 1.5 \mathrm{~nm}$ and c) Pore Volume $>1.0 \mathrm{~nm}$. Reproduced from (Presser et al., 2011)with permission of The Royal Society of Chemistry.

If ultramicropore volume has proven to influence the adsorption capacity of the activated carbons no clear relationship between the BET surface area and the adsorption capacity has been reported for pressures up to $0.1 \mathrm{MPa}$ (Presser et al., 2011; Serafin et al., 2017; Yin et al., 2013). The potential theory indicates that $\mathrm{CO}_{2}$ adsorption happens with micropore filling followed by capillary condensation and liquefaction with increasing pressure, it is expected then that at high pressure the BET surface area and total pore volume gain influence the $\mathrm{CO}_{2}$ adsorption. Drage et al. reported that at a pressure of 4.1 $\mathrm{MPa}$ a linear relationship between the $\mathrm{CO}_{2}$ adsorption capacity of activated carbons and the BET surface area can be found (Drage et al., 2009)

Another important factor to be considered when designing a carbonaceous porous material for carbon dioxide adsorption is the source of the raw material from which it will be produced. One of the main advantages of activated carbons is their versatility, any carbonaceous material can be converted into activated carbon with the main requirements being a high carbon content and low in ash, this arises the possibility of producing environmental friendly activated carbons based on lignocellulosic biomass. In this context, several efforts have been made to produce CAs from lignocellulosic resources with the aim of $\mathrm{CO}_{2}$ adsorption (table 6).

Table 6. Biowaste precursos used to prepare activated carbons along with their activation method, specific surface area and $\mathrm{CO}_{2}$ storage capacity (González-García, 2018).

\begin{tabular}{llll}
\hline Precursors & Activating Agent & Surface Area $\left(\mathrm{m}^{2} \mathrm{~g}\right)$ & Storage Capacity \\
\hline Oil cake/walnut & $\mathrm{CO}_{2}$ & 1207 & $34.72 \mathrm{ml} \mathrm{g}^{-1}$ \\
Coconut shell & $\mathrm{CO}_{2}$ & 371 & $1.8 \mathrm{mmol} \mathrm{g}^{-1}$ \\
& & & \\
\hline
\end{tabular}




\begin{tabular}{llcc}
\hline Almond-shell & $\mathrm{CO}_{2}$ & 862 & $2.7 \mathrm{mmol} \mathrm{g}^{-1}$ \\
Olive stone & $\mathrm{CO}_{2}$ & 1215 & $3.1 \mathrm{mmol} \mathrm{g}^{-1}$ \\
Coffee residue & $\mathrm{CO}_{2}$ & 593 & $2.4 \mathrm{mmol} \mathrm{g}^{-1}$ \\
Rice husk & $\mathrm{ZnCl}_{2}$ & 927 & $1.3 \mathrm{mmol} \mathrm{g}^{-1}$ \\
Peanut shell & $\mathrm{KOH}$ & 956 & $4.0 \mathrm{mmol} \mathrm{g}^{-1}$ \\
Sunflower seed & $\mathrm{KOH}$ & 1790 & $4.6 \mathrm{mmol} \mathrm{g}^{-1}$ \\
Bamboo & $\mathrm{KOH}$ & 1846 & $4.5 \mathrm{mmol} \mathrm{g}^{-1}$ \\
Palm stone & & & $2.7 \mathrm{mmol} \mathrm{g}^{-1}$ \\
\hline
\end{tabular}

The selection of the raw materials prior to the activated carbon production is of main concern for the gas storage suitability of the adsorbent. Olivares-Marín et al. showed the importance of the careful selection of the precursor. The Authors compared the $\mathrm{CO}_{2}$ one sample of pre-consumer carpet and two samples of post-consumer sample under the same activation conditions finding that the presence of inorganic binders in the precursor can result in a lower micropore volume lowering then the $\mathrm{CO}_{2}$ adsorption capacity between the samples from $13.8 \mathrm{wt} \%$ to $3.7 \mathrm{wt} \%$. Hao et al. obtained similar findings when comparing activated carbons obtained from grass cuttings, house manure, organic waste from beer production and bio-sludge from a wastewater treatment plant. The activated carbons produced from grass cutting and horse manure showed higher $\mathrm{CO}_{2}$ adsorption capacities due to a larger volume of ultramicropores (Hao et al., 2013). Munusamy et al. showed that using carboxyl methyl cellulose sodium salt and soluble starch as binders to convert a powdered mango seed shell derived activated carbon into extruded form they could enhance the maximum $\mathrm{CO}_{2}$ equilibrium adsorption capacity from $14.3 \mathrm{wt} . \%$ to $21.3 \mathrm{wt} . \%$ at $0.1 \mathrm{MPa}$ and $273 \mathrm{~K}$ explained by the formation of surface functionality by the binders on the extruded AC (Munusamy et al., 2015). 
In addition to the precursor nature, the optimal operating conditions of the activation process need to be determined since they can significantly affect the adsorption capacity of the AC. There are two possible activation paths for producing ACs, chemical activation and physical activation. Chemical activation using $\mathrm{KOH}, \mathrm{H}_{3} \mathrm{PO}_{4}$ or $\mathrm{ZnCl}_{2}$ is usually preferred since it results in hierarchical porous structures with high surface areas it also consumes less energy as the chemical activation temperature is between 600 and $800^{\circ} \mathrm{C}$ versus 800 to $1000^{\circ} \mathrm{C}$ for physical activation. Chemical activation has the additional advantage that it can be done in one stage where carbonization and impregnation of the precursor are done simultaneously, while physical activation involves a first step of carbonization and a second step where the material is activated in the presence of oxidants such as air, $\mathrm{CO}_{2}$ and steam (Singh et al., 2017; Wang and Kaskel, 2012).

Song et al. compared different activation methods and conditions for corn stalk based ACs. The ACs produced by physical activation at different activation concentrations or activation times presented surface areas lower than $500 \mathrm{~m}^{2} \mathrm{~g}^{-1}$ while chemical activation resulted in slightly higher surface areas (up to $639.8 \mathrm{~m}^{2} \mathrm{~g}^{-1}$ ), additionally the chemical activated carbons also showed higher micropore volumes. These two factors resulted in higher $\mathrm{CO}_{2}$ uptakes of chemical activated carbons than physical activated ones (Fig. 9). Between all the samples a maximum carbon dioxide adsorption capacity of 7.33 wt.\% was obtained (Song et al., 2015). Alabadi et al. were able to obtained highly porous activated carbons by chemical activation with $\mathrm{KOH}$ of a starch and gelatin $1: 1 \mathrm{mix}, \mathrm{CO}_{2}$ capture capacity of 3.8 $\mathrm{mmol} \mathrm{g}^{-1}$ at $298 \mathrm{~K}$ and $0.1 \mathrm{MPa}$ was obtained (Alabadi et al., 2015). Using also $\mathrm{KOH}$ activation to produce a pine nut-shell-derived activated carbon a high $\mathrm{CO}_{2}$ uptake of $5.0 \mathrm{mmol} \mathrm{g}^{-1}$ at $273 \mathrm{~K}$ and $0.1 \mathrm{MPa}$ was determined by Deng et al. (Deng et al., 2014). $\mathrm{A} \mathrm{CO}_{2}$ adsorption of $5.22 \mathrm{mmol} \mathrm{g}^{-1}$ at $293 \mathrm{~K}$ and $0.1 \mathrm{bar}$, one of the highest reported $\mathrm{CO}_{2}$ adsorption uptakes for carbonaceous materials, was obtained by $\mathrm{KOH}$ chemical activation of Coca-Cola as a source of biomass by Boyjoo et al. (Boyjoo et al., 2017). 

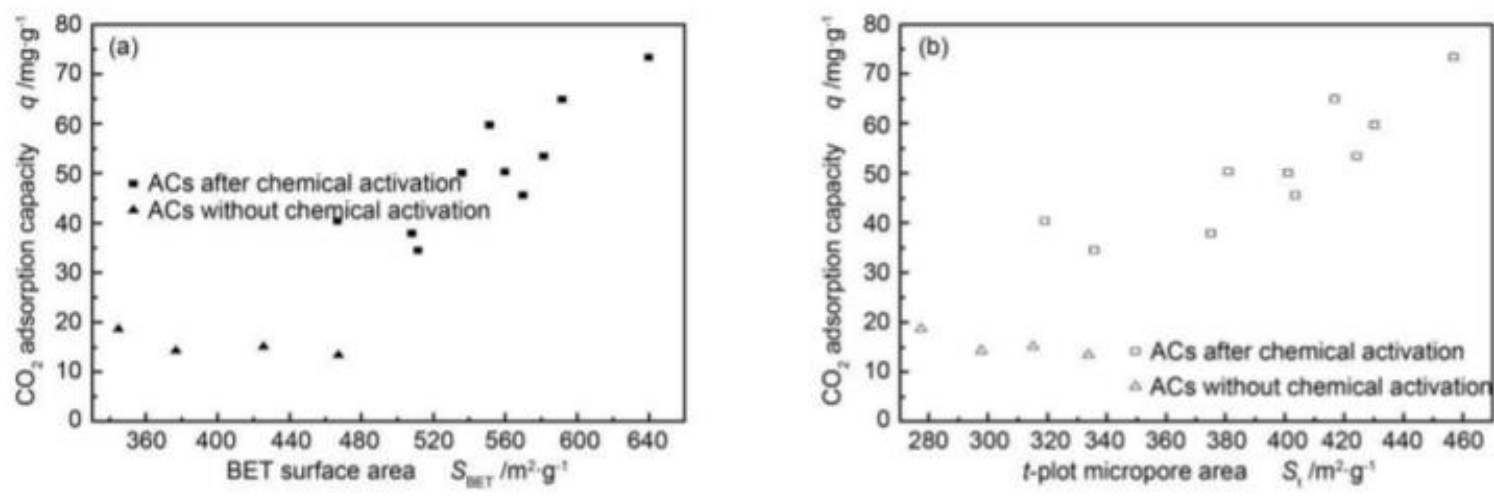

Fig. 9 Effect of a) BET surface area and b) $t$-plot micropore area on $\mathrm{CO}_{2}$ adsorption capacity at $298 \mathrm{~K}$ for chemical activated (squares) and physical activated (triangles) activated carbons from corn stalk Reprinted from(Song et al., 2015), Copyright (2015) with permission from Elsevier.

Typical activated carbons show weak affinity towards carbon dioxide with an adsorption capacity of surrounding 5 wt.\% at $298 \mathrm{~K}$ and a pressure of $0.01 \mathrm{MPa}$ (nearly the $\mathrm{CO}_{2}$ partial pressure of postcombustion gas) (Lee and Park, 2015). This value however, can be improved by chemical modification of the AC's surface. One possibility is to introduce Lewis bases onto the activated carbon surface which favors the $\mathrm{CO}_{2}$ adsorption due to its acidic properties. Nitrogen enrichment has been reported to be an effective way for introducing basic groups on the AC. Meng et al. reported a $\mathrm{CO}_{2}$ adsorption capacity of up to $17.7 \%$ wt. at $298 \mathrm{~K}$ and $0.01 \mathrm{MPa}$ when treating a polypyrrole activated carbon with $\mathrm{NaOH}$, they reported that the adsorption capacity was both a function of the nitrogen content and the micropore volume (Meng and Park, 2014). Other works reported the same dependence between the carbon dioxide capacity and both the textural properties and N content (Tiwari et al., 2017; Yaumi et al., 2018).

When introducing nitrogen functionalities the presence of oxygen surface groups is desirable, since they will act as anchoring sites for the nitrogen groups. Caglayan et al. studied the effect of different oxidation and heat treatments on the formation of $\mathrm{N}$ surface groups. They found that the $\mathrm{CO}_{2}$ adsorption capacity was enhanced by $\mathrm{Na}_{2} \mathrm{CO}_{3}$ impregnation of the air oxidized and nitric acid oxidized AC. They reported that sodium atoms $(\mathrm{Na})$ have $\mathrm{CO}_{2}$ sorption ability and that the oxidation with 
$\mathrm{HNO}_{3}$ provided anchoring sites for $\mathrm{Na}$ atoms (Caglayan and Aksoylu, 2013). Shafeeyan et al. compared the $\mathrm{CO}_{2}$ adsorption capacity of a heat-treated under nitrogen $\mathrm{AC}$ without pre-oxidation and amination of pre-oxidized AC (Shafeeyan et al., 2011).The samples that were not pre-oxidized presented a higher BET surface area, pore volume and micropore volume. This behavior is due to the thermal decomposition of functional groups inside the pores. Furthermore, when the sample is previously oxidized there is a blockage of the micropores entrances by oxygen and also a collapse of some pore walls leading to a decrease of the BET surface area and the micropore volume. However, if the oxidation step is done at high temperature $\left(800^{\circ} \mathrm{C}\right)$ the oxygen surface groups are decomposed and the textural properties are recovered (Fig. 10, sample OXA-800). They found a clear relationship between both micropore volumes and nitrogen content with the $\mathrm{CO}_{2}$ adsorption capacity.
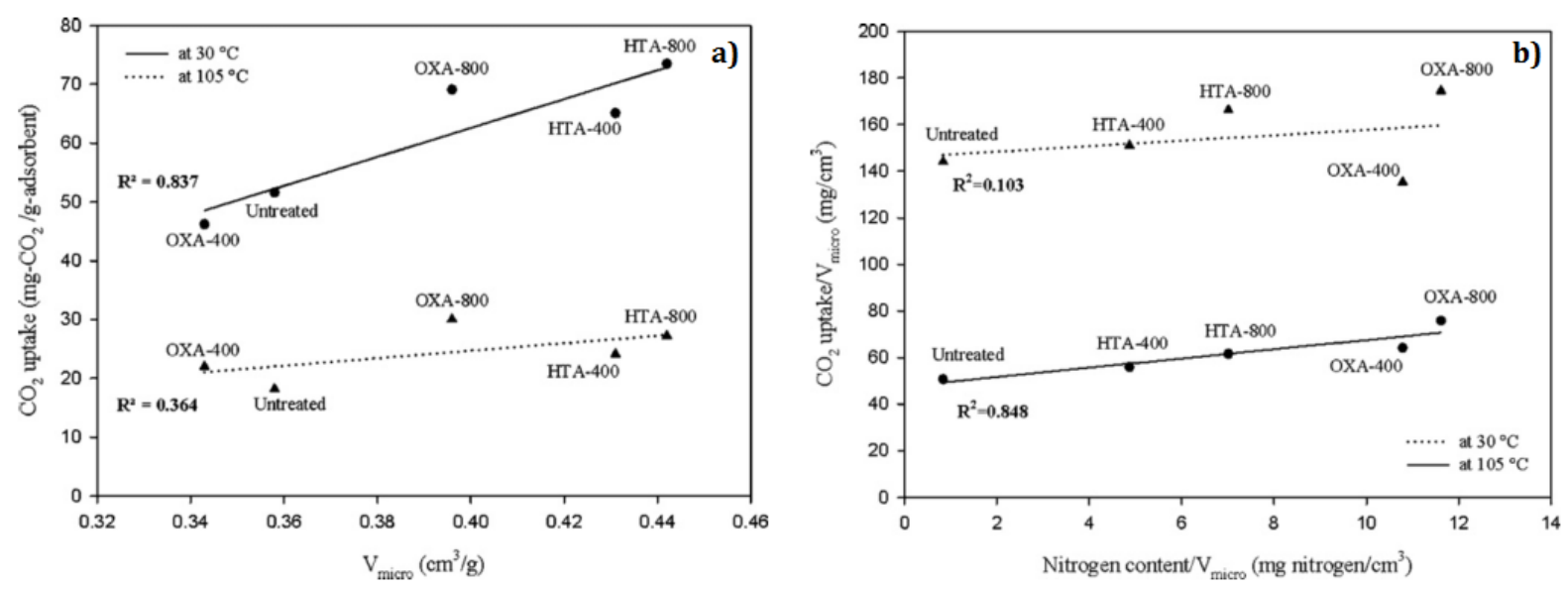

Fig. 10 Relationship between the $\mathrm{CO}_{2}$ capture capacity and a) micropore volume, b) nitrogen content (N\%). OXA-400 and OXA-800: Pre-oxidized samples aminated at 400 and $800{ }^{\circ} \mathrm{C}, \mathrm{HTA}-400$ and HTA800: Heat treated samples aminated at 400 and $800{ }^{\circ} \mathrm{C}$ without pre-oxidation. Reprinted from Publication (Shafeeyan et al., 2011), Copyright (2011), with permission from Elsevier.

Seema et al. showed that upon Sulphur (S) doping of microporous carbonaceous materials the $\mathrm{CO}_{2}$ adsorption capacity can be increased. They found a correlation between the BET surface area, micropore volume and oxidized Sulphur surface groups with the carbon dioxide adsorption capacity. A maximum adsorption capacity of $4.5 \mathrm{mmol} \mathrm{g}^{-1}$ was reached (Seema et al., 2014). Xia et al. also 
reported an increased on the $\mathrm{CO}_{2}$ adsorption capacity after S-doping of microporous carbons, they obtained a maximum adsorption capacity of $2.46 \mathrm{mmol} \mathrm{g}^{-1}$ when a $\mathrm{S}$ content of $6.56 \%$ was present and of $1.69 \mathrm{mmol} \mathrm{g}^{-1}$ when there was no Sulphur atoms on the carbonaceous material.

It is then that even if the $\mathrm{CO}_{2}$ adsorption capacity of activated carbons is greatly influenced by the BET surface area and the volume of narrow micropores $(<0.8 \mathrm{~nm})$, the surface chemistry can also play an important role in the search of better materials for the $\mathrm{CO}_{2}$ separation and storage. Different functionalities can be added to the surface of the adsorbent that will participate in the adsorption process trough acid-base interactions and polarizability of the carbon dioxide molecules.

In addition to nitrogen and sulphur doping, activated carbons can be treated with metal oxides resulting in chemical reactions between the $\mathrm{CO}_{2}$ molecules and the metal oxides at elevated temperatures. Published works include impregnation of activated carbons with alkaline metals such as $\mathrm{Mg}$ and $\mathrm{Ca}$, and transition metals like $\mathrm{Cu}, \mathrm{Co}, \mathrm{Ni}, \mathrm{Fe}, \mathrm{Cr}$ and $\mathrm{Zn}$ (Somy et al., 2009; Son et al., 2005; Yong and Mata, 2001). Son et al. determined the $\mathrm{CO}_{2}$ adsorption capacity of metal impregnated activated carbons to decrease in the order of $\mathrm{Mg}>\mathrm{Ca}>\mathrm{Co}=\mathrm{Cu}>\mathrm{Ni}$ (impregnated metal) (Son et al., 2005). Using $\mathrm{Zn}^{2+}$ as a promotor (Fig. 11), Somy et al. tested the adsorption behavior of activated carbons impregnated by $\mathrm{Fe}_{2} \mathrm{O}_{3}$ and $\mathrm{Cr}_{2} \mathrm{O}$, finding a $20 \%$ increase of the $\mathrm{CO}_{2}$ adsorption capacity upon $\mathrm{Cr}_{2} \mathrm{O}$ impregnation (compared with raw $\mathrm{AC}$ ); meanwhile $\mathrm{Fe}_{2} \mathrm{O}_{3}$ impregnation was not effective (Somy et al., 2009). It has been reported that an acidic treatment prior to the metal impregnation can further increase the carbon dioxide adsorption, the acid groups will oxidize the samples and provide oxygen surface groups that can form metal complexes with the metal ions (Hosseini et al., 2015). 


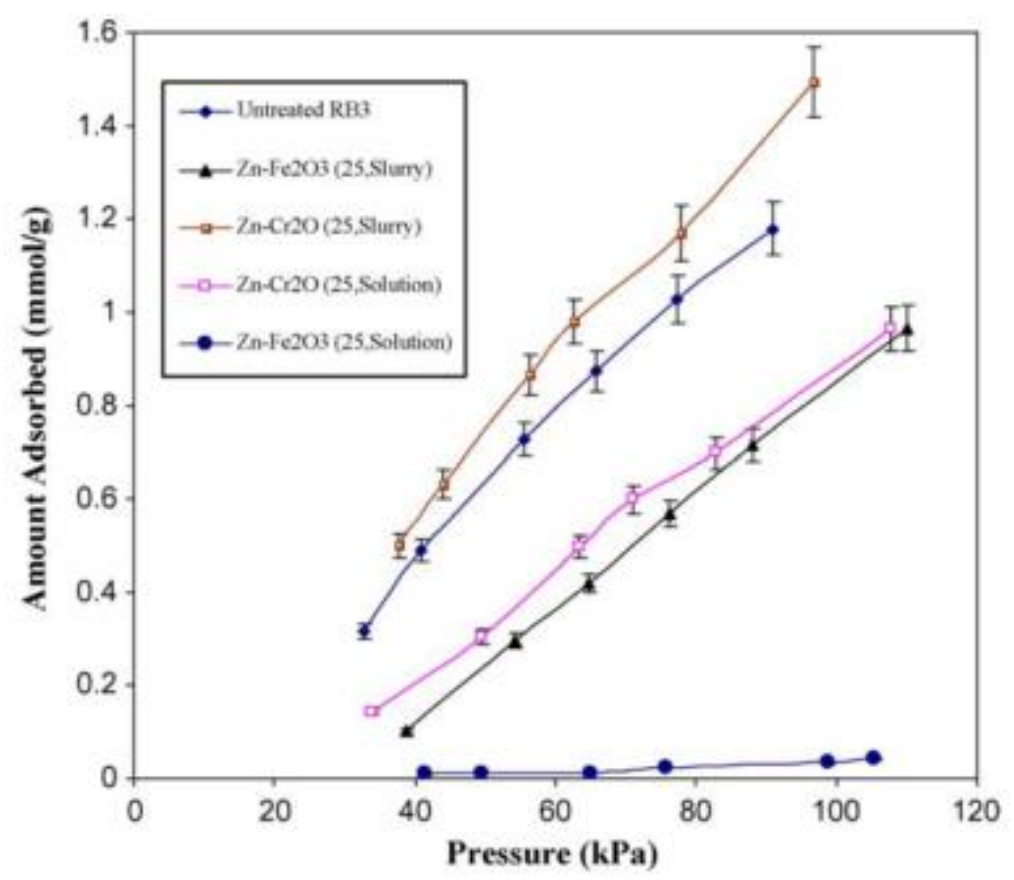

Fig. $11 \mathrm{CO}_{2}$ adsorption isotherms of $\mathrm{Zn}^{+2}$-metal oxide samples prepared by solution and slurry impregnation methods. Reprinted from (Somy et al., 2009), Copyright (2009), with permission from Elsevier.

\subsection{Hydrogen Storage}

One way to reduce the greenhouse gas emissions can be achieved by designing suitable adsorbents to efficiently remove gases like $\mathrm{CO}_{2}$ and $\mathrm{CH}_{4}$ from the atmosphere. In addition, renewable clean energy sources (water, wind, solar) are currently developed to replace at long term the fossil fuels. However, an important disadvantage of renewable energy sources is their intermittence which requires efficient energy storage systems to store and release energy when needed. Hydrogen, is one of the renewable resources that can help in addressing the growth of energy demand without contributing to the global climate change. Hydrogen is an abundant element in fossil hydrocarbons and all organic matter. In its pure molecular form, $\mathrm{H}_{2}$, hydrogen is a colorless, odorless, non-toxic gas which produces only water vapor when used in to a fuel cell, making it a clean fuel. $\mathrm{H}_{2}$ has the advantage to posses the highest energy density among common fuels by weight.; Unfortunately, gaseous $\mathrm{H}_{2}$ has the lowest energy density by volume and present a risk of explosion in contact with the air. Therefore, developing safe, 
efficient and inexpensive hydrogen storage system with acceptable gravimetric and volumetric energy densities is still an objective for researchers to achieve(Andrews and Shabani, 2014).

At present, two methods are mainly used for the storage of large quantities of hydrogen. The storage in the gaseous state is done at a high pressure (700 bars) in bottles which is rather heavy and bulky. The storage in the liquid state requires a temperature of $20 \mathrm{~K}$ and therefore expensive cooling devices along with significant losses by evaporation (boil-off phenomenon). Both methods present significant problems related to the storage under pressure and the high explosive potential of hydrogen in air (above $4 \%$ by volume). Third solution is solid hydrogen storage, with significant safety and volume capacity advantages.

US Department of Energy (DOE) targeted a minimum gravimetric and volumetric requirement for onboard hydrogen storage systems. However, the current market and technology scenario have led to some revisions and changes in targets. In 2010 , the targeted storage system has a gravimetric density of $4.5 \mathrm{wt} \%(1.5 \mathrm{kWh} / \mathrm{kg})$ and volumetric density of $28 \mathrm{~g} / \mathrm{L}(0.9 \mathrm{kWh} / \mathrm{L})$, while for 2015 , the targeted gravimetric density was changed to $5.5 \mathrm{wt} \%(1.8 \mathrm{kWh} / \mathrm{kg})$, and the volumetric density was revised to be $40 \mathrm{gH}_{2} / \mathrm{L}$ (1.3 kWh/L) (Md Arshad et al., 2016).

As highlighted in Figure 12(Durbin and Malardier-Jugroot, 2013), the current hydrogen storage technology do not meets the DOE standards. This may be related to fundamental limitations of each particular storage method: i) the gaseous $\mathrm{H}_{2}$ requires a large volume to be stored, ii) the liquid hydrogen requires low temperatures and evaporates easily, iii) metal hydrides are heavy and present thermodynamic hydrogen release limitation and IV) adsorbent materials present low adsorption capacities at room temperature and pressure. Therefore, significant efforts are made to improve these storage techniques and to develop new storage methods. 


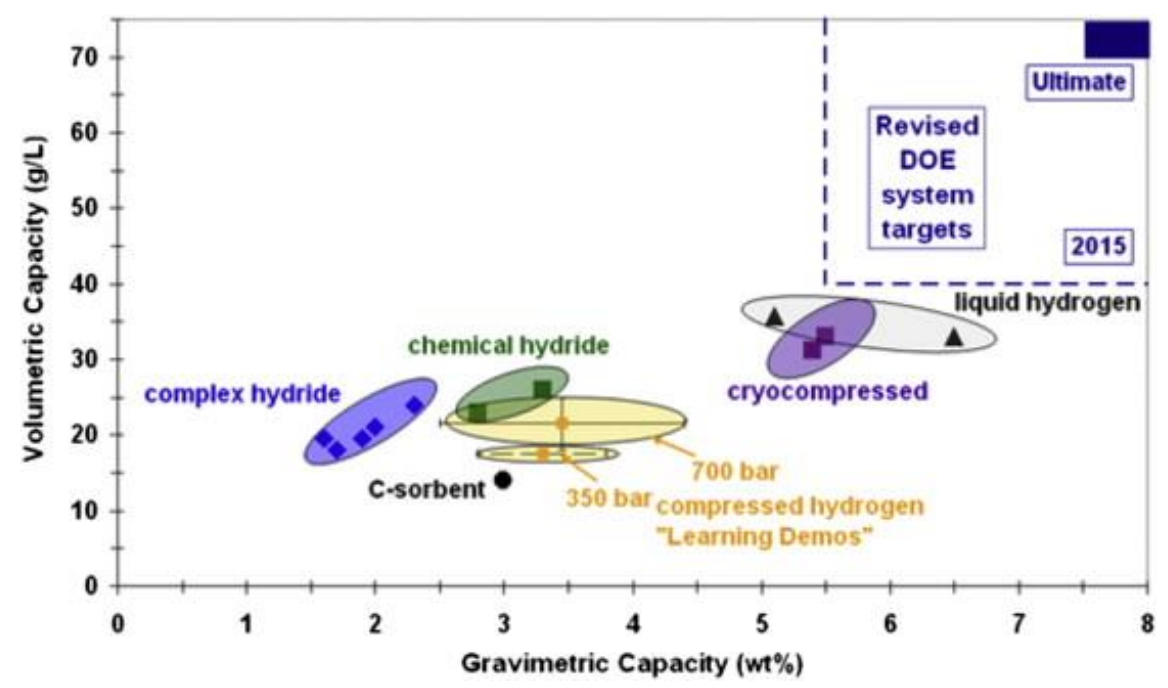

Fig. 12 Ranking of current hydrogen storage technologies by volumetric and gravimetric capacities showing the DOE 2015 and ultimate targets.Reprinted from (Durbin and Malardier-Jugroot, 2013), Copyright (2013), with permission from Elsevier.

A great interest has been focused on hydrogen physisorption on different adsorbents including zeolites, metal organic framework, and carbon-based materials. Particularly, carbon adsorbents exhibit several advantages compared to other adsorbents, i.e., low cost, low densities, fast kinetics, and complete hydrogen reversibility( $V$ et al., 2010). Moreover, the hydrogen sorption capacity can be comparable or even higher than MOFs and zeolites (Builes et al., 2011).Among the carbonaceous materials, activated carbons (ACs) have been widely investigated as $\mathrm{H}_{2}$ storage materials due to their easiest preparation process combined with more developed porous structure when compared to nanostructured carbons (carbon nanotubes, carbon nanofibers, template carbons).

Biomass is widely employed as precursor to obtain the carbon mainly to their eco-friendly nature, widespread availability and high adsorption/desorption rates (Agarwal et al., 1987; Masika and Mokaya, 2013). Several biomass precursors have been explored, i.e., cellulose, corncob, rice husk, olive bagasse, starch etc. (see Table 7), however, simple pyrolysis of biomass results in low surface area carbon materials and in most of the cases an activation step is usually used in order to develop the porosity. Mainly, two types of activation procedure based on physical $\left(\mathrm{CO}_{2}\right.$ or water steam) and 
chemical activation ( $\left.\mathrm{KOH}, \mathrm{H}_{3} \mathrm{PO}_{4} \ldots\right)$ are used. In particularly, as revealed by Table 7-9 gathering several literature data, chemical activation with $\mathrm{KOH}$ is the most used since it leads to highly microporous activated carbons with well developed surface areas (up to $3700 \mathrm{~m}^{2} \cdot \mathrm{g}^{-1}$ ). In addition, the chemical activation requires lower activation temperatures and shorter reaction time than physical activation, but on the contrary it requires a supplementary washing step in order to remove the impurities created during the activation process.

The development of the porosity is a consequence of carbon oxidation (etching) due to the redox reaction between potassium hydroxide and carbon with the formation of carbonates, release of volatiles $\left(\mathrm{H}_{2}, \mathrm{CO}_{\times}\right)$and intercalation of $\mathrm{K}$, according to the following equations(Choi and Park, 2015; Wang et al., 2009):

$6 \mathrm{KOH}+2 \mathrm{C}=>2 \mathrm{~K}+3 \mathrm{H}_{2}+2 \mathrm{~K}_{2} \mathrm{CO}_{3}$

$\mathrm{K}_{2} \mathrm{CO}_{3}+\mathrm{C}=>\mathrm{K}_{2} \mathrm{O}+2 \mathrm{CO}$

$\mathrm{K}_{2} \mathrm{O}+\mathrm{C}=>2 \mathrm{~K}+\mathrm{CO}$

Other parameters such as the carbon precursor type, the activation agent type/ amount, and the activation temperature/time using during the carbon preparation are the main factors determining the porosity development and the surface chemistry of the materials. Both parameters are of prime importance when come to design efficient adsorbents for hydrogen storage applications and will be discussed further in more details.

\subsubsection{Influence of adsorption conditions ( $T, P)$}

The hydrogen storage studies are mainly focused at $77 \mathrm{~K}$, due to the weak interaction between molecular hydrogen and solids. The amount of hydrogen stored at room temperature is very low, while it can consistently increase at low temperature, typically $77 \mathrm{~K}$, that is, the temperature of liquid nitrogen. At elevated temperatures such as room temperature, the storage capacity was found to vary linearly with pressure, following Henry's law, while at 77K the adsorption isotherm of all samples could be satisfactorily explained using the Langmuir model (Figure 13). 


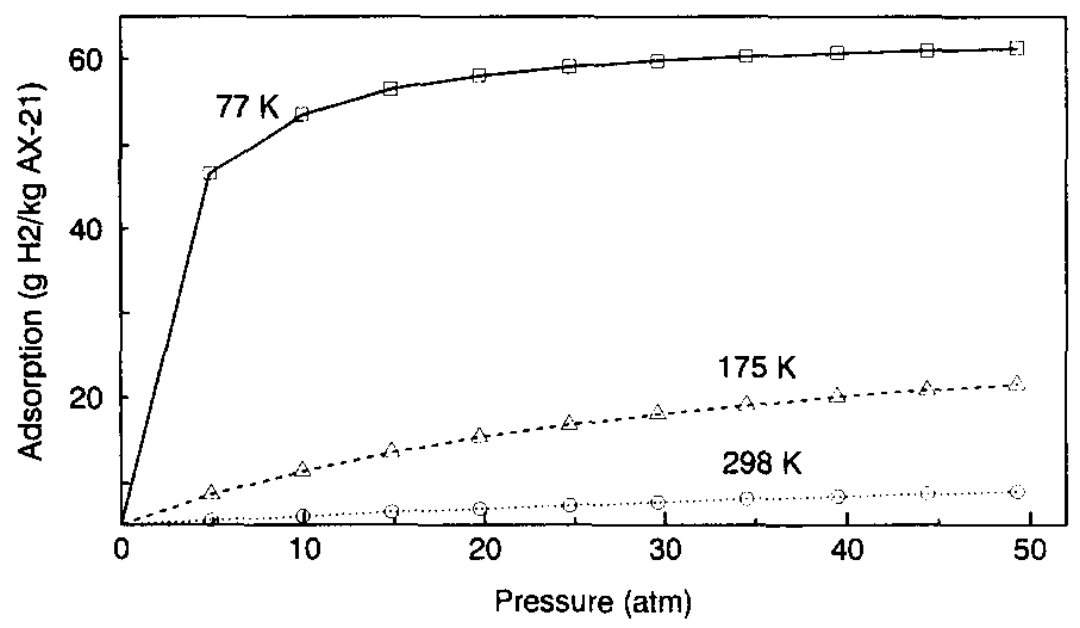

Fig. 13Adsorption isotherms of $\mathrm{H}_{2}$ on the activated carbons AX-21 at different temperatures. Reprinted from (Chahine and Bose, 1994), Copyright (1994), with permission from Elsevier .

Therefore, at room temperature the hydrogen adsorption capacity is very low. This trend can be also seen as well in Table 7, where several hydrogen adsorption capacities of several biomasses derived activated carbon are shown. It can be observed that the maximum achieved capacity at room temperature and high pressure is only slightly superior to $1 \mathrm{wt} \%$ even if the surface area of the carbon is very high $\left(\sim 3000 \mathrm{~m}^{2} \cdot \mathrm{g}^{-1}\right)$.

Therefore, much more studies are made in cryogenic conditions, i.e. $77 \mathrm{~K}$ and different pressures. It is therefore worth to discuss the influence of the porosity on the adsorption capacity in such conditions.

Table 7. Activated carbon derived from different biomasses along with their textural properties and hydrogen adsorption capacity at room temperature (398-303 K) and different pressures.

\begin{tabular}{cccccccc}
\hline & Activating & BET SSA & $\mathrm{V} \mu$ & $\mathrm{H}_{2}$ ads. & & \\
Precursor & & $\left(\mathrm{m}^{2} / \mathrm{g}\right)$ & $\left(\mathrm{cm}^{3} / \mathrm{g}\right)$ & Capacity & $\mathrm{T}(\mathrm{K})$ & $\mathrm{P}(\mathrm{bar})$ & Refs \\
& agent & & & & & \\
& & & & & &
\end{tabular}




\begin{tabular}{|c|c|c|c|c|c|c|c|}
\hline Cellulose & $\mathrm{KOH}$ & 3771 & - & 0.5 & 298 & 20 & $\begin{array}{c}\text { (Blankenship li et } \\
\text { al., 2017) }\end{array}$ \\
\hline $\begin{array}{c}\text { Olive } \\
\text { pomace }\end{array}$ & $\mathrm{KOH}$ & 1269 & 0.48 & 1.22 & 298 & 204 & $\begin{array}{c}\text { (Heo and Park, } \\
\text { 2015) }\end{array}$ \\
\hline Jute fibers & $\mathrm{KOH}$ & 1224 & 0.43 & 1.2 & 303 & 40 & $\begin{array}{c}\text { (Ramesh et al., } \\
\text { 2017) }\end{array}$ \\
\hline $\begin{array}{c}\text { Tamarind } \\
\text { seeds }\end{array}$ & $\mathrm{KOH}$ & 1784 & 0.64 & 1.36 & 303 & 60 & $\begin{array}{c}\text { (Ramesh et al., } \\
\text { 2015) }\end{array}$ \\
\hline $\begin{array}{c}\text { Coffee } \\
\text { shell }\end{array}$ & $\mathrm{KOH}$ & 3149 & - & 0.91 & 298 & 140 & (G. Li et al., 2016) \\
\hline $\begin{array}{c}\text { Olive } \\
\text { bagasse }\end{array}$ & $\mathrm{CO}_{2}$ & 1185 & 0.45 & 0.63 & 298 & 200 & $\begin{array}{c}\text { (Bader and } \\
\text { Abdelmottaleb, } \\
\text { n.d.) }\end{array}$ \\
\hline
\end{tabular}

\subsubsection{Influence of porosity}

Table 8 present the hydrogen adsorption capacities at 77K and 1 bar, for activated carbons issued from several biomasses (beer lees, rice husks, starch hemp stem etc) activated with $\mathrm{CO}_{2}$ or $\mathrm{KOH}$. At a first glance, it can be noticed that the hydrogen capacities are comprised between 1.97 and $3.2 \mathrm{wt} . \%$, for activated carbon materials possessing specific BET surface area ranged between 687 and $3771 \mathrm{~m}^{2} \cdot \mathrm{g}^{-1}$ and micropore volumes between 0.3 and $1.19 \mathrm{~cm}^{3} \cdot \mathrm{g}^{-1}$. In order to evidence any correlation between the hydrogen adsorption capacity and the SSA and the micropore volume, several data were collected from the references listed in Table 8 and plotted in Figure 14.

Table 8. Activated carbon derived from different biomasses along with their textural properties and hydrogen adsorption capacity at $77 \mathrm{~K}$ and 1 bar. 


\begin{tabular}{|c|c|c|c|c|c|c|c|}
\hline Precursor & $\begin{array}{c}\text { Activating } \\
\text { agent }\end{array}$ & $\begin{array}{l}\text { BET SSA } \\
\left(\mathrm{m}^{2} \cdot \mathrm{g}^{-1}\right)\end{array}$ & $\begin{array}{c}V \mu \\
\left(\mathrm{cm}^{3} \cdot \mathrm{g}^{-1}\right)\end{array}$ & $\begin{array}{c}\mathrm{H}_{2} \\
\text { ads. } \\
\text { Capaci } \\
\text { ty } \\
\text { (wt\%) }\end{array}$ & $\begin{array}{l}\mathrm{T} \\
(\mathrm{K})\end{array}$ & $\begin{array}{c}\text { P } \\
\text { (bar) }\end{array}$ & Refs. \\
\hline $\begin{array}{l}\text { Fruit } \\
\text { bunch }\end{array}$ & $\mathrm{CO}_{2}$ & 687 & 0.297 & 1.97 & 77 & 1 & (Md Arshad et al., 2016) \\
\hline Beer lees & $\mathrm{KOH}$ & 1927 & 0.70 & 2.92 & 77 & 1 & $\begin{array}{c}\text { (Balathanigaimani et al., } \\
\text { 2018) }\end{array}$ \\
\hline Rice husks & $\mathrm{KOH}$ & 2682 & 0.792 & 2.85 & 77 & 1 & (Heo and Park, 2015) \\
\hline Cellulose & $\mathrm{KOH}$ & 3771 & - & 3.9 & 77 & 1 & $\begin{array}{c}\text { (Andrews and Shabani, } \\
\text { 2014) }\end{array}$ \\
\hline Starch & $\mathrm{CO}_{2}$ & 3281 & 1.1 & 2.3 & 77 & 1 & (Y. Li et al., 2016) \\
\hline Fungi & $\mathrm{KOH}$ & 2137 & 0.87 & 2.4 & 77 & 1 & (Wang et al., 2014) \\
\hline Corncob & $\mathrm{KOH}$ & 3708 & 1.14 & 3.2 & 77 & 1 & (Liu et al., 2014) \\
\hline Chitosan & $\mathrm{KOH}$ & 2840 & 1.06 & 2.88 & 77 & 1 & $\begin{array}{c}\text { (Wróbel-Iwaniec et al., } \\
\text { 2015) }\end{array}$ \\
\hline & & & & & & & (Wang et al., 2016) \\
\hline Surcrose & $\mathrm{KOH}$ & 1552 & 0.72 & 2.5 & 77 & 1 & (Choi and Park, 2015) \\
\hline Hemp & $\mathrm{KOH}$ & 3078 & 1.13 & 3.18 & 77 & 1 & (Zhang et al., 2017) \\
\hline Stem & & & & & & & \\
\hline
\end{tabular}

As can be noticed, the capacity increases rather linearly from 1.5 to $3.2 \mathrm{wt} \%$ when increasing the surface area from 468 to $3078 \mathrm{~m}^{2} \cdot \mathrm{g}^{-1}$. Similar trend of capacity improvement is observed with the increase of the microporous volume, however, in this case the data point are more scattered. This behavior maybe due to the different pore size or surface chemistries of these materials which induce also an effect on the adsorption capacity as it will be presented latter in the chapter. 
Table 9. Activated carbon derived from different biomasses along with their textural properties and hydrogen adsorption capacity at low temperature, $77 \mathrm{~K}$ and different high pressures.

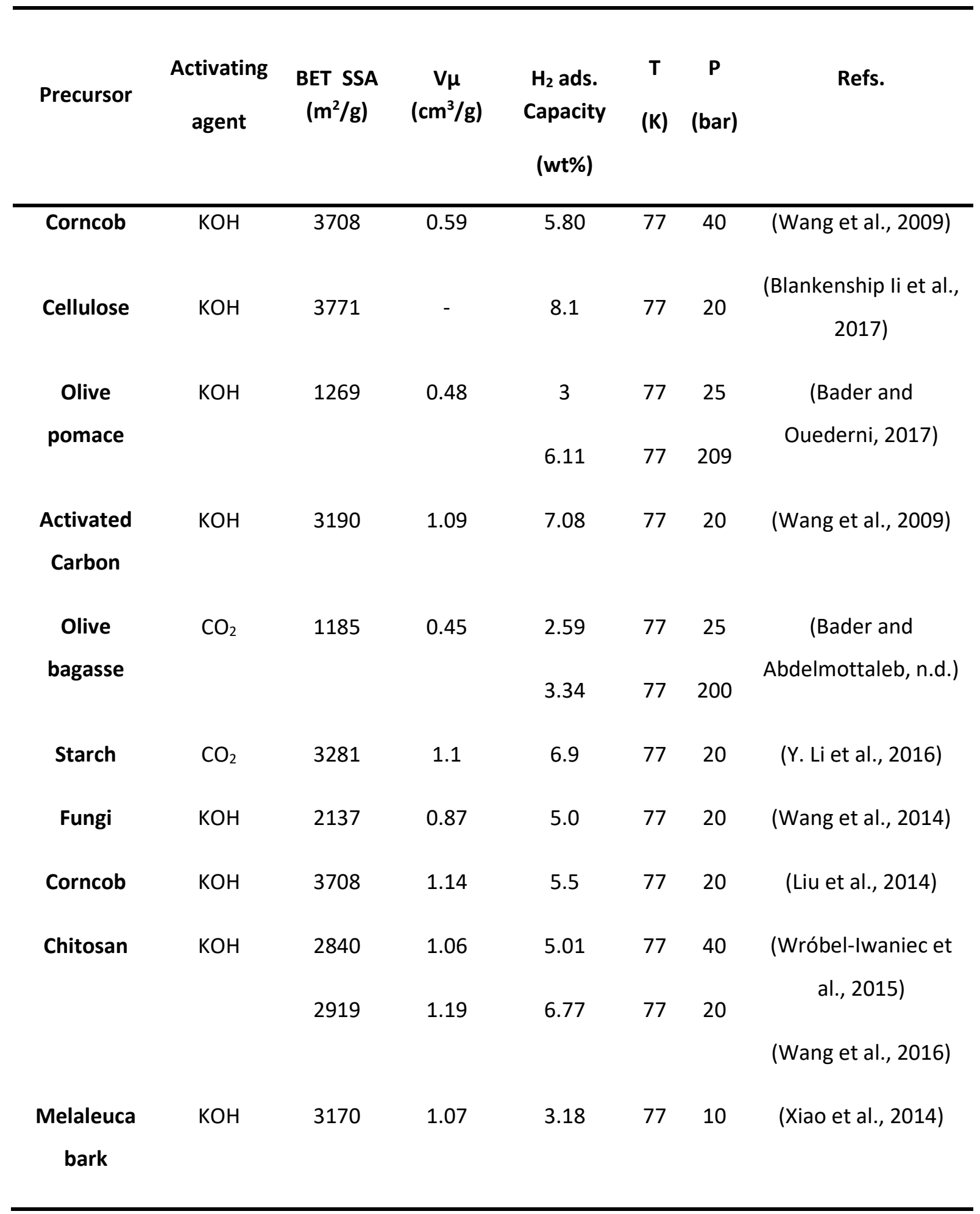



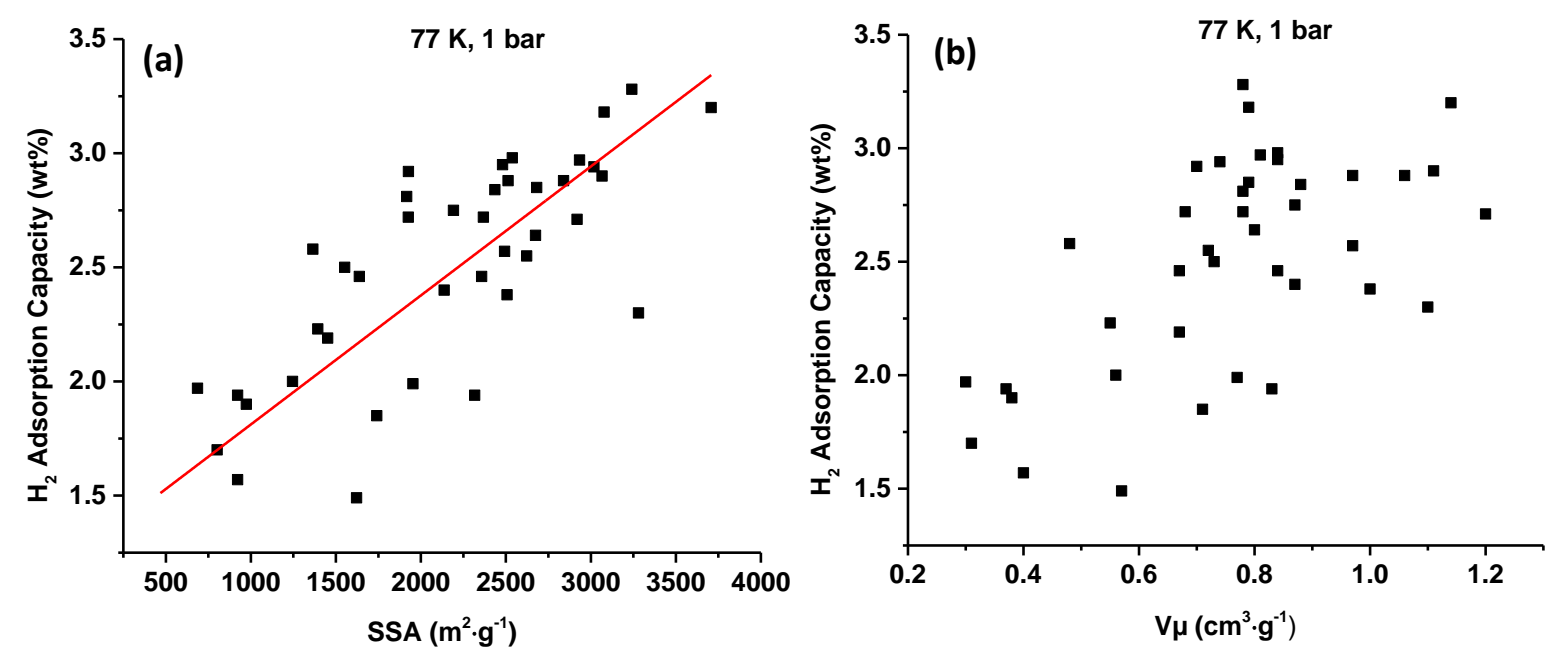

Fig. 14Correlation between the hydrogen adsorption capacity at $77 \mathrm{~K}$ and $1 \mathrm{bar}$, and the specific surface area (a) and microporous volume (b) (literature data are extracted from references listed in Table 8).

The pressure as mentioned has an important influence on the hydrogen adsorption capacity. In Table 3, several literature data are collected at $77 \mathrm{~K}$ a high pressures (20 - 209 bars) for several activated carbons. The adsorption capacities are much higher than at atmospheric pressure and may reach 8.1 wt.\% by combining a high surface area as well. Nevertheless, if one plot the values form Table 3 references (Figure 4) it can be clearly seen a linearly relationship between the adsorption capacity and the specific surface area and the microporous volume. The capacity increases from 4.2 to 8.1 by increasing the BET surface from 1452 to $3771 \mathrm{~m}^{2} \cdot \mathrm{g}^{-1}$. 

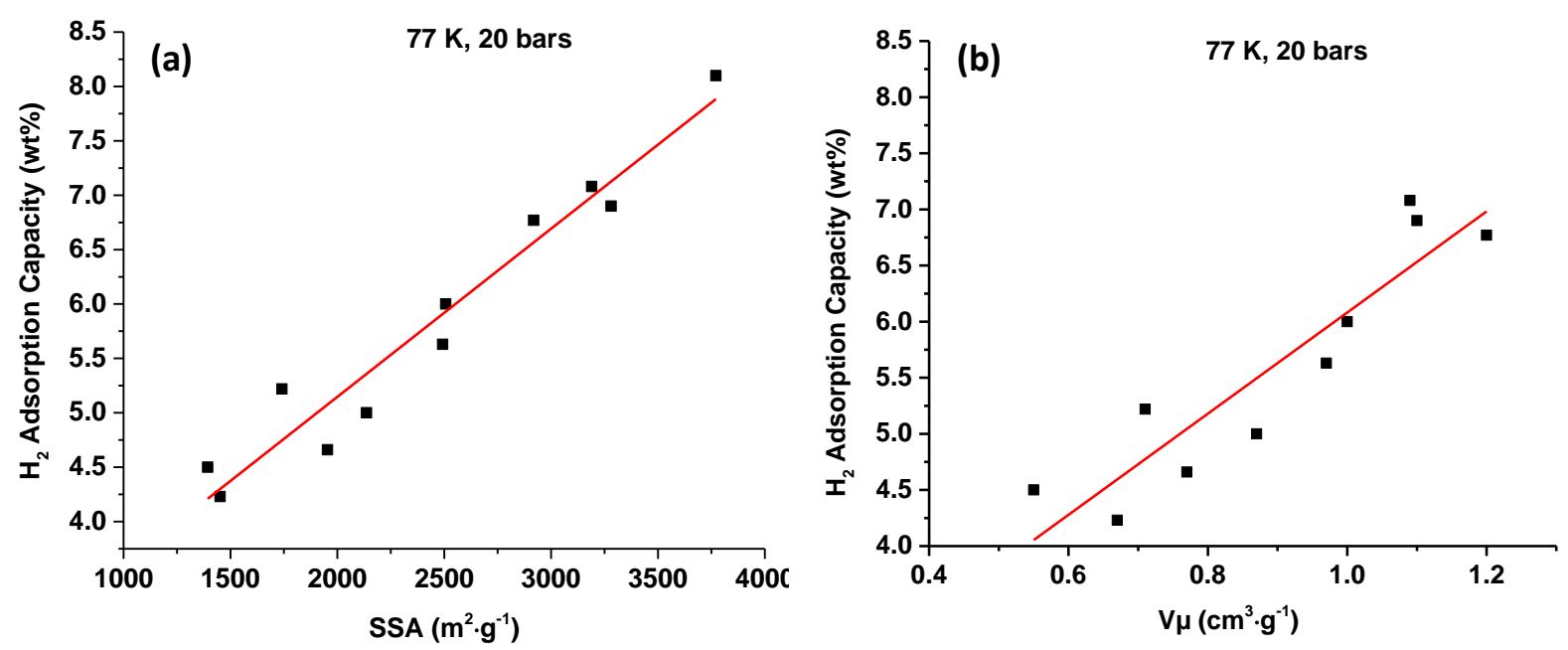

Fig. 15 Correlation between the hydrogen adsorption capacity at 77K and 20 bars, and the specific

surface area (a) and microporous volume (b) (literature data are extracted from references listed in Table 9).

Indeed the experimental conditions $(\mathrm{T}, \mathrm{P})$ and the textural properties of carbon materials are the main important parameters influencing the hydrogen adsorption capacity. Both the specific surface area and the microporous volume affect the adsorption capacity, and generally an increase of the capacity with the increase of the textural values is observed but a linear correlation is difficult to obtain when gathering many different carbon materials. This may be mainly due to the fact that the carbon materials may exhibit different pore size and surface chemistries. If one focus on one series of activated carbons derived from the same precursor for instance chitosan biopolymer, Wrobel-Iwaniectry et al. (Wróbel-Iwaniec et al., 2015) correlate the $\mathrm{H}_{2}$ adsorption capacity at $77 \mathrm{~K}$ and 1 bar with BET surface area $\left(\mathrm{S}_{\mathrm{BET}}\right)$, total pore volume $\left(\mathrm{V}_{\mathrm{T}}\right)$ and micropore volume $\left(\mathrm{V}_{\mathrm{DRN} 2}\right)$ and linear relationship was observed with a correlation coefficient $\left(R^{2}\right)$ being the highest for the microporous volume (0.916). The same trend was observed at high pressures (40 bars) and in this case the correlation coefficient $\left(R^{2}\right)$ is even higher than at low pressure (1bar), i.e., 0.961 for microporous volume. This is in line with the observations made in Figure 14 and 15 where several activated carbon hydrogen sorption capacities were presented. Similar observations showing the importance of micropores (pores smaller than $2 \mathrm{~nm}$ ) 
on the hydrogen adsorption have been shown by other authors as well (Schaefer et al., 2016; Wang et al., 2009; Yang et al., 2012).
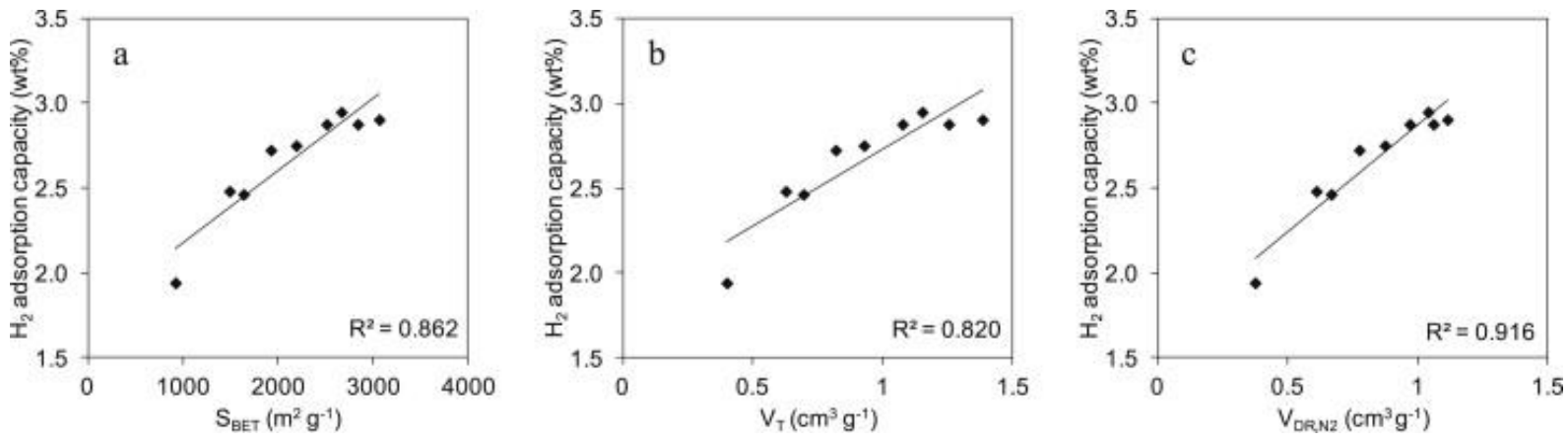

Fig. 16 The variation in hydrogen adsorbed at $77 \mathrm{~K}$ and 1 bar pressure with a) BET surface area, b) total pore volume and c) total micropore volume for activated carbons derived from chitosan. Reprinted from (Wróbel-Iwaniec et al., 2015), Copyright (2015), with permission from Elsevier.

Further investigation lead to the conclusion that $\mathrm{H}_{2}$ storage capacity correlates better with the ultramicropore volume (volume of pore having size $<0.7 \mathrm{~nm}$ ) than the surface area of carbon materials. For example, Texier Mandoki et al.(Texier-Mandoki et al., 2004) have shown that the hydrogen adsorption capacity of activated carbons is directly related to its $\mathrm{CO}_{2}$ micropore volume (Figure $17 \mathrm{a}$ ). This work emphasizes the importance of the presence of a homogeneous narrow microporosity (dpore $\leq 0.7 \mathrm{~nm}$ ) for the hydrogen adsorption and the necessity to complete the $\mathrm{N}_{2}$ adsorption characterizations of carbon materials by the $\mathrm{CO}_{2}$ adsorption measurements at $273 \mathrm{~K}$, in order to obtain a better knowledge of the whole microporosity range of activated carbons. However, in most of the available literature data, the $\mathrm{N}_{2}$ adsorption is systematically used while the $\mathrm{CO}_{2}$ adsorption is only marginally employed. To get more deep understanding in the contribution of porosity to the hydrogen capacity, Shafer et al.(Schaefer et al., 2016) gather the adsorption capacity of different activated carbon at room temperature and $77 \mathrm{~K}$ and different pressure. As seen in Figure $17 \mathrm{~b}$, the main contribution to $\mathrm{H}_{2}$ uptake is due to the narrowest micropores $(0.5-0.7 \mathrm{~nm})$. When increasing the pore width the hydrogen uptake gradually decreases. The authors pointed also that the pore diameter through the overlap of the adsorption potentials is significantly less important at $77 \mathrm{~K}$ than at $298 \mathrm{~K}$, 
temperature at which the adsorption potential needs to be very high to allow hydrogen adsorption at the carbon surface.
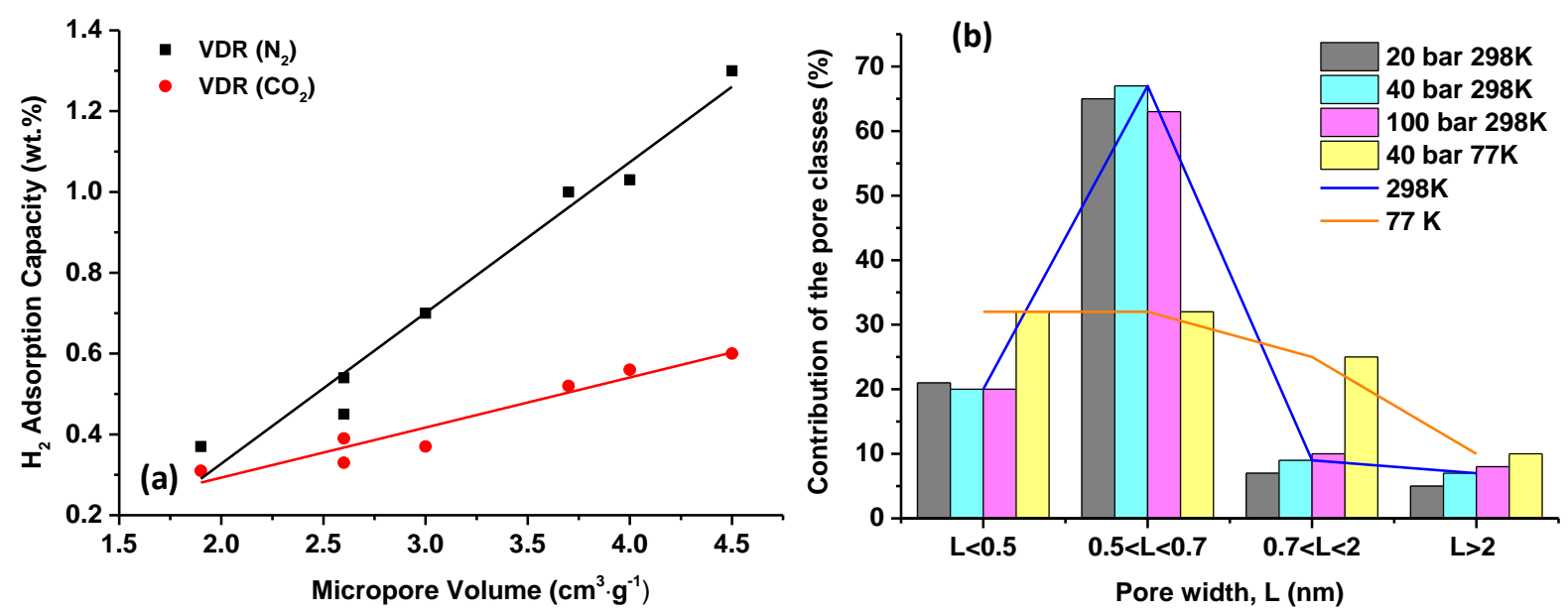

Fig. $17 \mathrm{H}_{2}$ adsorption capacity at $77 \mathrm{~K}$ and 10 bar versus $\mathrm{N}_{2}$ and $\mathrm{CO}_{2}$ micropore volume. Adapted from (Texier-Mandoki et al., 2004), Copyright (2004), with permission from Elsevier.(a) and contribution of each pore diameter to the hydrogen up-take at different temperatures and pressures. Adapted from (Schaefer et al., 2016), Copyright (2016), with permission from Elsevier.

The main conclusions about these studies is that smaller pores $\sim 0.7 \mathrm{~nm}$ are more convenient for hydrogen storage. Therefore, several studies focused on the effect of pore size on hydrogen uptake in high surface area porous carbons and the following optimum pore diameters for $\mathrm{H}_{2}$ storage. However, Sethia and Sayari (Sethia and Sayari, 2016) and Masika and Mokaya (Masika and Mokaya, 2013) pointed out that in many studies the pore size vary in the same time with the pore volume or surface area, therefore, ambiguities may exist when studying the effect of pore size for such materials. In this sense, Sethia and Sayari (Sethia and Sayari, 2016)concluded that the high hydrogen uptake is associated for the activated carbon having the most important cumulative volume of ultra-micropores (<0.7). Two materials exhibited identical total pore volume $\left(0.64 \mathrm{~cm}^{3} / \mathrm{g}\right.$ vs. $\left.0.65 \mathrm{~cm}^{3} / \mathrm{g}\right)$ and BET surface area $\left(1312 \mathrm{~m}^{2} / \mathrm{g}\right.$ vs. $1342 \mathrm{~m}^{2} / \mathrm{g}$ ) has been prepared and it has been determined that they exhibited 21.8\% difference in the hydrogen uptake. The authors attributed this significant decrease in hydrogen uptake to the occurrence of a broader PSD with larger micropores (0.63 vs. $0.59 \mathrm{~nm})$ together with 
$28.6 \%$ decrease in ultra-micropore volume (0.21 vs $0.27 \mathrm{~cm}^{3} / \mathrm{g}$ ). Masika and Mokaya (Masika and Mokaya, 2013) showed that the excess and total hydrogen uptake (at 77K and 20 bar) of activated carbons with identical surface areas of $3340 \mathrm{~m}^{2} / \mathrm{g}$ (Fig 18 left), increased from 3.7 and 5.4 wt \% (31 ^ pore size sample), to 4.8 and 6.3 wt \% ( $23 \AA ̊$ pore size sample), and to 6.3 and 7.3 wt \% for a $12 \AA$ pore size sample. The authors concluded that the excess hydrogen storage density $\left(\mu \mathrm{mol} \mathrm{H}_{2} \cdot \mathrm{m}^{-2}\right)$ of the carbons decreases linearly with pore size (Figure 18 right).
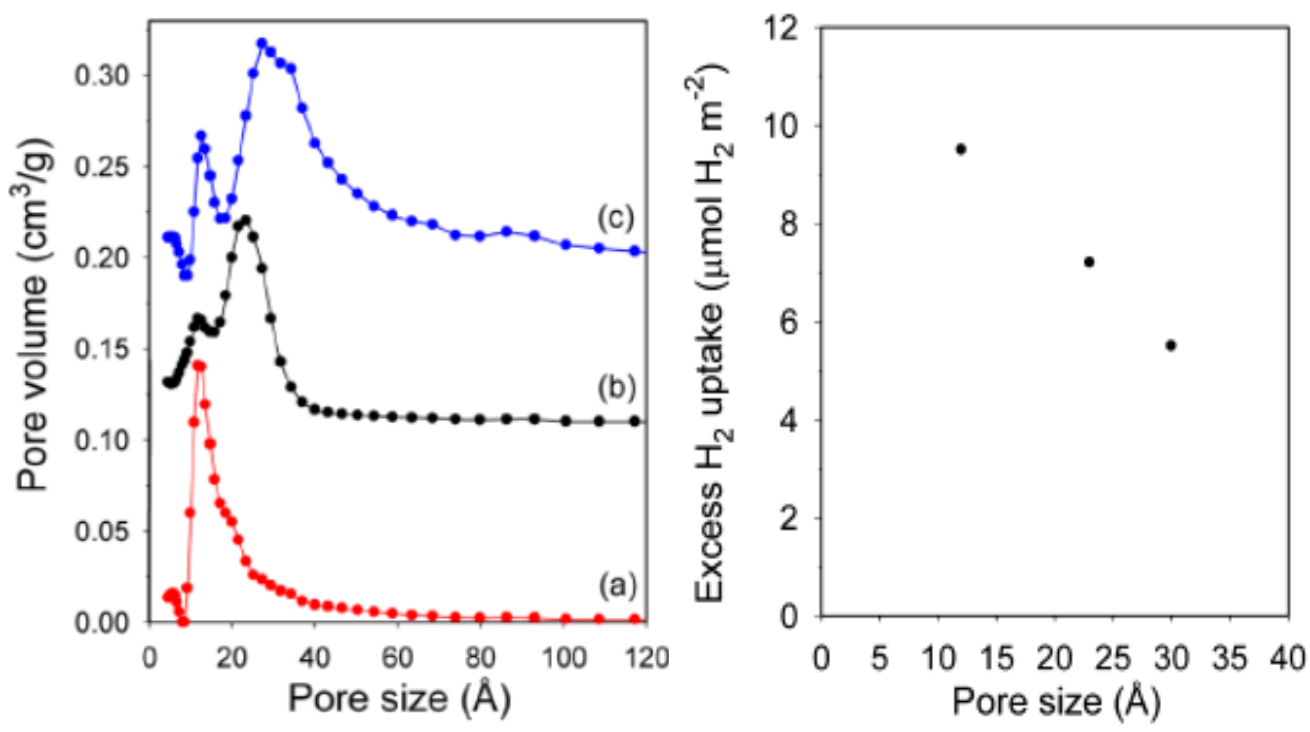

Fig. 18Pore size distribution curves (left) of porous carbon materials along with their hydrogen adsorption up-take vs. pore size (right). Reprinted with permission from (Masika and Mokaya, 2012) Copyright (2012) American Chemical Society.

\subsubsection{Influence of surface chemistry}

The interaction between adsorbed hydrogen and carbons is very weak and can be improved via functionalization of the surface with heteroatoms. The researches have demonstrated that the surface chemical properties of activated carbons have an important role in their sorption capacity. The amount of hydrogen adsorbed on activated carbons depends on the surface groups present on activated carbons; however, the presented literature results are somehow contradictory. Agarwal et al. (Agarwal et al., 1987)prepared activated carbons with modified amount of oxygen surface groups by thermal 
oxidation at different temperatures and for different time periods. The nature and the amount of formed oxygen complexes were determined by Boehm titration, and it was found that the surface oxygen complexes affect the amount of hydrogen adsorbed on the surface, i.e., the amount of hydrogen adsorbed increases with the amount of surface acidic complexes. Concerning the influence of basic complexes groups the authors did not found any trend with the amount of hydrogen adsorbed. Georgakis et al (Georgakis et al., 2007)used a theoretical approach via molecular dynamic simulation in order to understand the impact of oxygen functional groups on the hydrogen adsorption capacity. Six types of commons oxygen groups found on porous carbon have been used (carboxyl, carbonyl, lactones, anhydrides, phenols and quinones).They end up to the conclusion that the oxygen functional groups induce a decrease in hydrogen adsorption capacity and this effect is more pronounced with the narrow pores (Figure 19a).They accounted this behavior to mainly three factors, i.e., increase of weight due to the oxygen, steric hindrance effects and weaker oxygen-hydrogen interactions compared to carbon-hydrogen (Figure 19b).
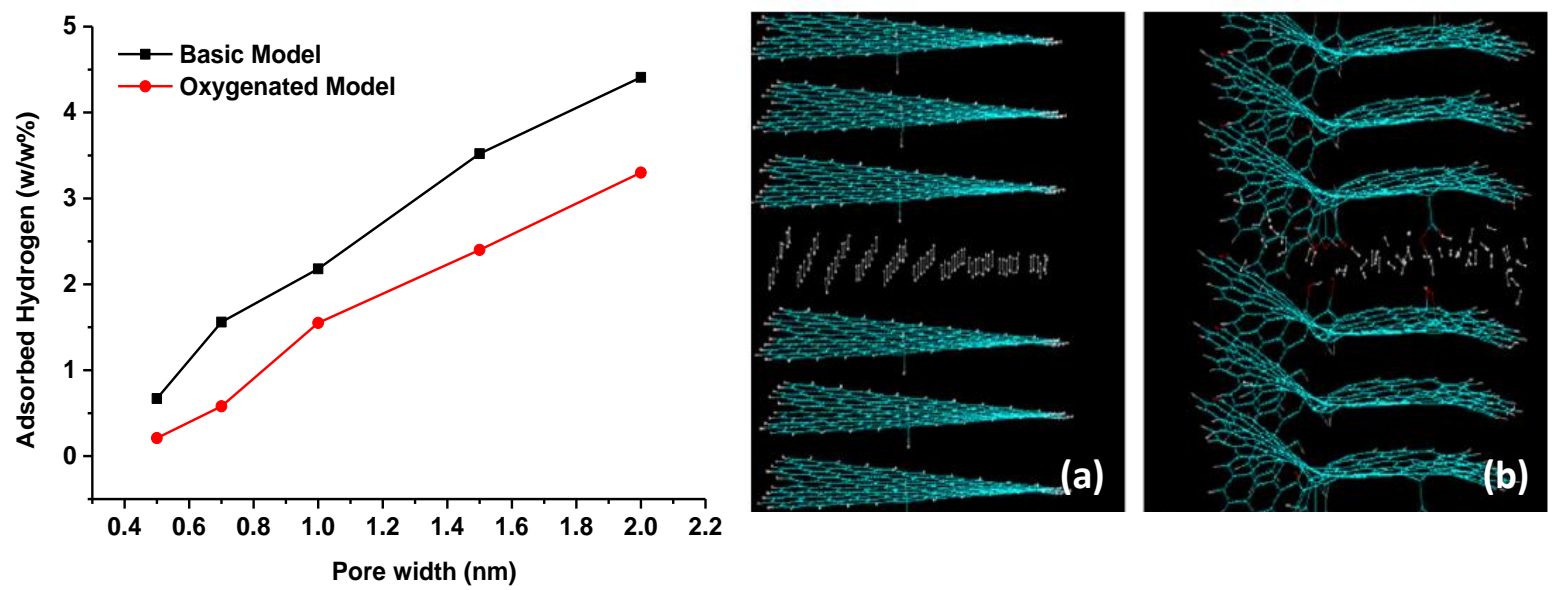

Fig. 19 Correlation between the adsorbed hydrogen amount for basic carbon (no oxygen functional groups and oxygenated model (contains 6 types of oxygen groups) vs. the pore size obtain by molecular dynamics simulation (left); Hydrogen adsorption snapshots for the pore size of $0.7 \mathrm{~nm}$ (a) purely carbonaceous material; (b) oxygenated materials when the adsorption simulation is complete in the basic model (right). Readapted (left) and reprinted (right) from (Georgakis et al., 2007), Copyright (2007), with permission from Elsevier. 
From experimental point of view, Huang et al. (Huang et al., 2010) found the same trend, i.e. hydrogen uptake decreases when the carbons present oxygen functional groups. The authors used activated carbon derived from litchi wood which was post-modified by nitric acid or hydrogen peroxide at various temperatures to enable the formation of oxygen functional groups. In some cases however, the drastic oxidation conditions lead not only to the introduction of functional groups but also to the porosity collapsing and therefore, to the hydrogen uptake decrease (Figure 20 a). The authors found that the hydrogen capacity is not depending on the amount of the basic groups, but rather on the amount of acidic groups. It has been observed as well that the hydrogen capacity is significantly suppressed when increasing the acidic group amounts more than $0.8 \mathrm{mmol} / \mathrm{g}$ (Figure 20b), this fact being also related to the simultaneous decrease of the specific surface area (Figure 20a).
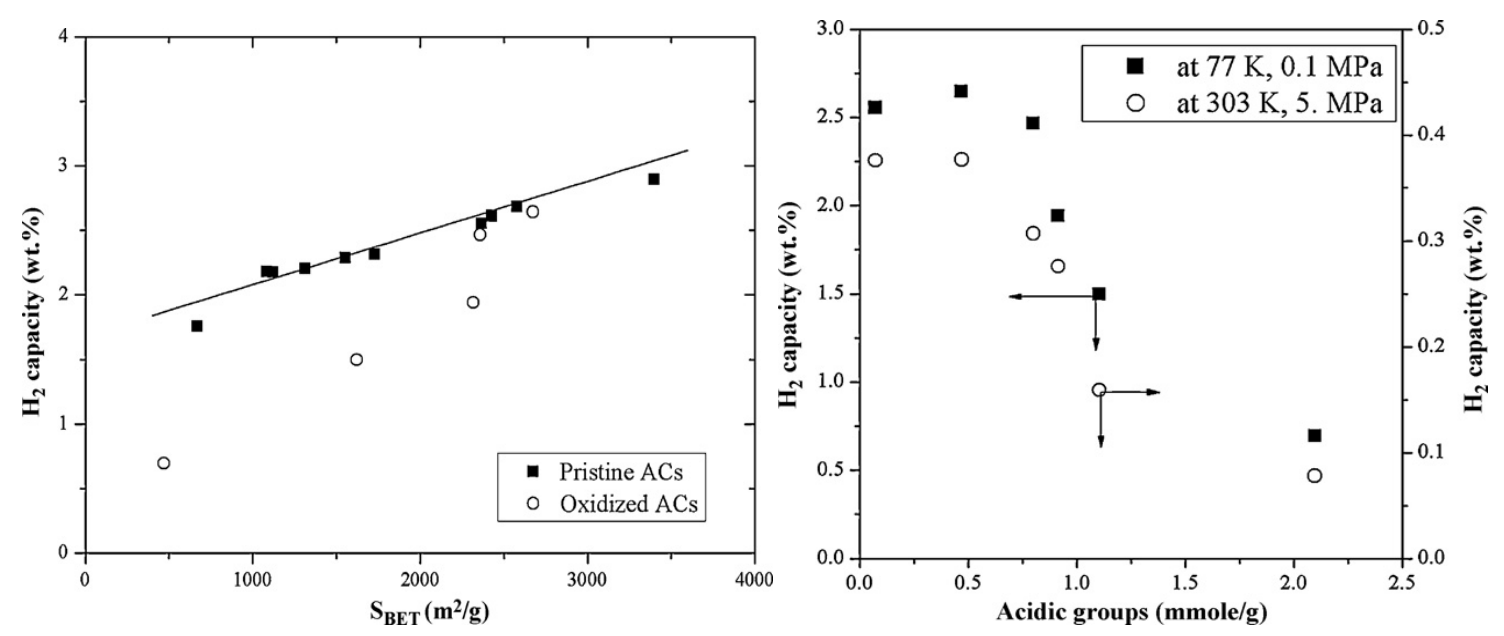

Fig. 20Comparison of hydrogen capacity of the pristine activated carbon and oxidized activated carbon (left) and effect of surface acidic groups on hydrogen capacity measured at different conditions (right). Reprinted from (Huang et al., 2010), Copyright (2010), with permission from Elsevier.

Many other authors found that the amount of hydrogen adsorbed remarkably decreased by oxidation of the carbons (Bleda-Martínez et al., 2008; Takagi et al., 2004; Zhao et al., 2005) and they accounted this to the decrease accessibility to aromatic $\mathrm{C}-\mathrm{C}$ bonds due to the pore blockage with the functional groups (Schimmel et al., 2003; Takagi et al., 2004). Some authors prove that the oxygen groups do not affect the hydrogen up-take since no significant differences were detected by comparing their capacity 
with that of pristine carbons(Llorens and Pera-Titus, 2009; Tellez-Juarez et al., 2014). However, recent works performed by Blankenship II et al.(Blankenship li et al., 2017) claim an opposite behavior. By using hydrothermally treated cellulose further activated with $\mathrm{KOH}$ at different temperatures (600$\left.800^{\circ} \mathrm{C}\right)$, highly porous carbon $\left(2000-3700 \mathrm{~m}^{2} \mathrm{~g}^{-1}\right)$ containing high amounts of oxygen (17.9-20.6 wt.\%) were prepared. This combination of high surface area and high amount of functional oxygen groups was reached at $700^{\circ} \mathrm{C}$ of activation (CA-4700) and allow improving the hydrogen up-take (Figure 21 a) significantly comparing to the reference activated carbon AX21. To explain this behavior, the isosteric heat of hydrogen adsorption (Qst) was measured (Figure 21 b) allowing an estimation of the strength of interaction between the hydrogen and carbon surface. As can be noticed, the isosteric heat of hydrogen adsorption is significantly much higher for the cellulose-derived activated carbons, CA (8 $10 \mathrm{KJ} / \mathrm{mol}$ ) compared to that of reference activated carbon, AX21 (5-6 KJ/mol). The authors accounted this difference not only to the porosity but also to the presence of oxygen functional groups.
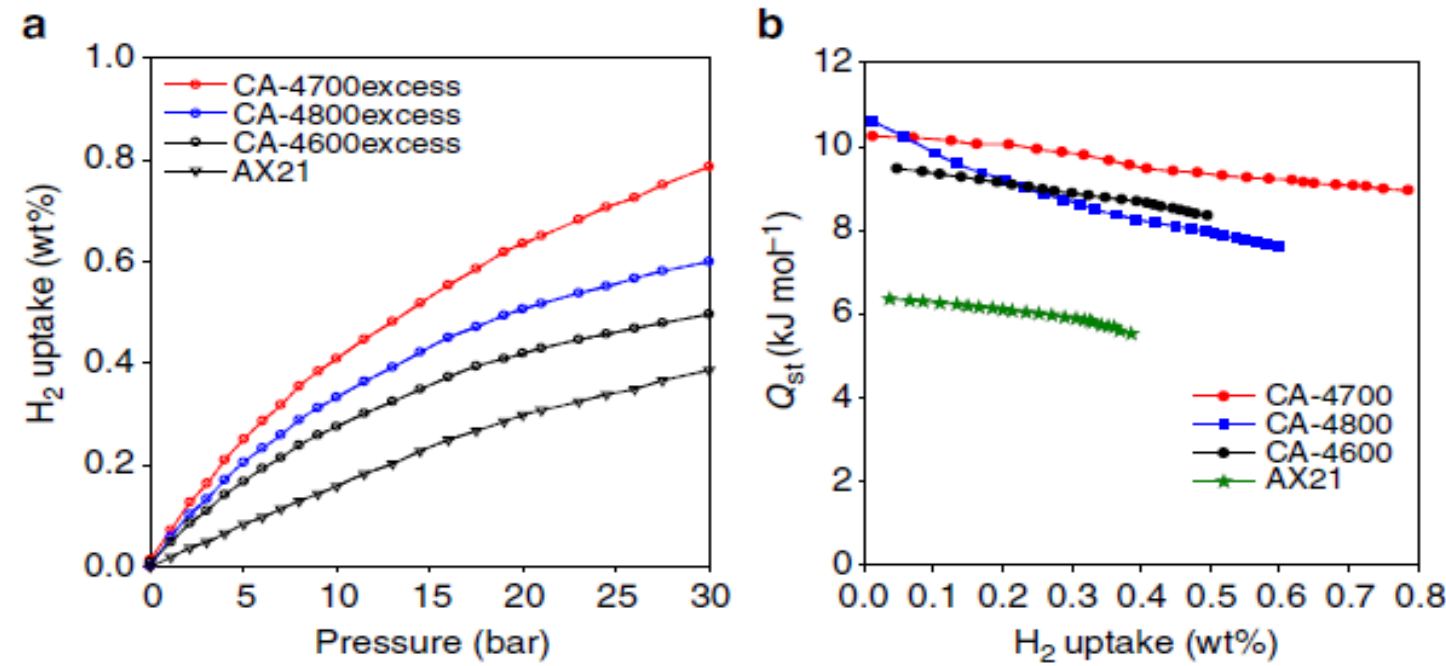

Fig. 21Hydrogen storage capacity at room temperature (a) and isosteric heat of hydrogen adsorption (b) of activated carbons derived from cellulose acetate and a commercially reference activated carbon AX21. Reprinted form (Blankenship li et al., 2017).

Taking therefore into consideration all these works showing contradictory results, one can be stated that the effect of oxygen groups on the hydrogen adsorption still need to be investigated in order to better understand it. Moreover, when other functional groups are present on the carbon surface, such nitrogen-based groups, the effect of these groups on hydrogen adsorption is still much difficult to 
assess. However, there are only few studies dedicated to the effect of nitrogen atoms on hydrogen storage performance. Wang et al. (Wang et al., 2016)used chitosan precursor, containing nitrogen in its skeleton to obtain $\mathrm{N}$-doped porous carbon through an activation process. The amount of nitrogen could be varied from 6.5 to $0.53 \mathrm{wt} \%$ by increasing the activation temperature from 600 to $800^{\circ} \mathrm{C}$. The authors found that the high $\mathrm{N}$-doping is beneficial for hydrogen adsorption at low pressure but it is detrimental at high pressure. It is worth to mention that high nitrogen contents are always accompanied by significant oxygen contribution. However, the authors did not took into consideration this aspect which may contribute as well to the observed hydrogen storage behavior.

Fonctionalisation of carbon with metal-based nanoparticles such as ( $\mathrm{Pd}, \mathrm{Pt}, \mathrm{Ni}$...) or with metal hydrides $\left(\mathrm{MgH}_{2}, \mathrm{LiBH}_{4}, \mathrm{LiAlH}_{4}\right)$ may further improve the hydrogen up-take by chemisorptions and/or spill-over effects (Figure 24), however, this is a large topic which will not be developed here but can be overviewed in a recent review (Ren et al., 2017).

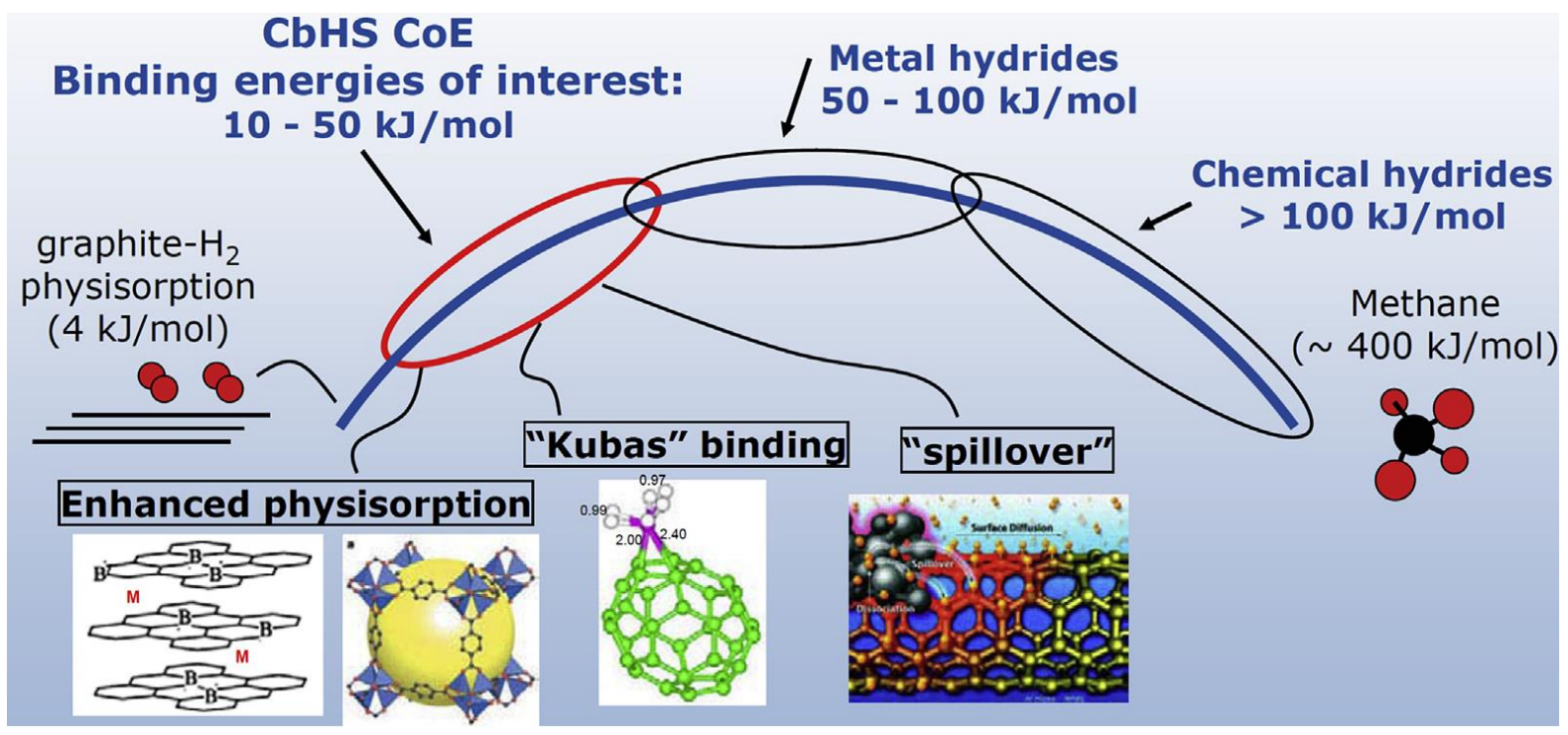

Fig. 24 Binding energies and the associated sorption mechanisms in different materials. Reprinted from (Dillon AC, et al.). 


\subsection{Conclusions}

From environmental and economic point of value the use of biomass to prepare carbon materials with tunable features is demonstrated in many works. Many sources of biomass or biomass waste were used and optimized activation conditions with physical or chemical agents afford to obtain materials with high specific surface area, high porous volume and tunable pore size characteristics, and various surface chemistries, highly desired for gas storage applications. For the three gases evaluated herein $\left(\mathrm{CH}_{4}, \mathrm{CO}_{2}\right.$ and $\left.\mathrm{H}_{2}\right)$, the adsorption capacities on carbon adsorbents show many similar trends. As demonstrated in many works, the adsorption capacity depends firstly on the available porosity, namely the specific surface area and in particularly microporous volume, the pore size with narrow distributions (0.5 $-0.8 \mathrm{~nm}$ ) being likely more favorable for achieving higher gas adsorption up-takes. In addition to the porosity, the carbon functional groups are also influencing the gas adsorption capacity. The oxygen, nitrogen and sulfur were widely studied and their influence on the gas up-take is not the same for all the gases. For $\mathrm{CO}_{2}$ adsorption, oxygen seems beneficial to increase the gas up-take while for hydrogen adsorption oxygen proved to be detrimental. Regarding the other heteroatoms $(\mathrm{N}, \mathrm{S})$, their impact was found more difficult to precisely demonstrate due to the complexity to design materials with similar texture and oxygen contents, which usually interferes and accounts also in the adsorption process. The impact of the morphology on the gas adsorption is not deeply addressed and deserves further investigations to elucidate its impacts on the materials density, gas diffusion and volumetric gas capacity. Beside the carbon characteristics that strongly influences the gas adsorption capacity, the analysis condition such as temperature and pressure has significant importance. Due to the week interactions of the gases with the carbon structure, the gas adsorption capacities at room temperature and atmospheric pressure or even high pressure, remain very small to meets the requirements of DEO departments. They can be however strongly improved at low temperature (77K) and high pressure achieving in some cases the capacities required by DEO. Nevertheless, such solution involving low temperature/high pressures remains expensive and not feasible for real life application. 


\section{References}

Agarwal, R.K., Noh, J.S., Schwarz, J.A., Davini, P., 1987. Effect of surface acidity of activated carbon on hydrogen storage. Carbon 25, 219-226. https://doi.org/10.1016/0008-6223(87)90119-9

Alabadi, A., Razzaque, S., Yang, Y., Chen, S., Tan, B., 2015. Highly porous activated carbon materials from carbonized biomass with high $\mathrm{CO}<\mathrm{inf}>2</ \mathrm{inf}>$ capturing capacity. Chem. Eng. J. 281, 606-612. https://doi.org/10.1016/j.cej.2015.06.032

Alonso, A., Moral-Vico, J., Abo Markeb, A., Busquets-Fité, M., Komilis, D., Puntes, V., Sánchez, A., Font, X., 2017. Critical review of existing nanomaterial adsorbents to capture carbon dioxide and methane. Sci. Total Environ. 595, 51-62. https://doi.org/10.1016/j.scitotenv.2017.03.229

Andrews, J., Shabani, B., 2014. The role of hydrogen in a global sustainable energy strategy. Wiley Interdiscip. Rev. Energy Environ. 3, 474-489. https://doi.org/10.1002/wene.103

Antoniou, M.K., Diamanti, E.K., Enotiadis, A., Policicchio, A., Dimos, K., Ciuchi, F., Maccallini, E., Gournis, D., Agostino, R.G., 2014. Microporous and Mesoporous Materials Methane storage in zeolite-like carbon materials. Microporous Mesoporous Mater. 188, 16-22. https://doi.org/10.1016/j.micromeso.2013.12.030

Arami-Niya, A., Wan Daud, W.M.A., S. Mjalli, F., Abnisa, F., Shafeeyan, M.S., 2012. Production of microporous palm shell based activated carbon for methane adsorption: Modeling and optimization using response surface methodology. Chem. Eng. Res. Des. 90, 776-784. https://doi.org/10.1016/j.cherd.2011.10.001

Bader, N., Abdelmottaleb, O., n.d. CO2 activation of olive bagasse for hydrogen storage. Environ. Prog. Sustain. Energy 36, 315-324. https://doi.org/10.1002/ep.12514

Bader, N., Ouederni, A., 2017. Functionalized and metal-doped biomass-derived activated carbons for energy storage application. J. Energy Storage 13, 268-276. https://doi.org/10.1016/j.est.2017.07.013

Bagheri, N., Abedi, J., 2011. Adsorption of methane on corn cobs based activated carbon. Chem. Eng. Res. Des. 89, 2038-2043. https://doi.org/10.1016/j.cherd.2011.02.002

Balathanigaimani, M.S., Haider, M.B., Jha, D., Kumar, R., Lee, S.J., Shim, W.G., Shon, H.K., Kim, S.C., Moon, H., 2018. Nanostructured Biomass Based Carbon Materials from Beer Lees for Hydrogen Storage [WWW Document]. URL https://www.ingentaconnect.com/contentone/asp/jnn/2018/00000018/00000003/art00121 (accessed 6.21.18).

Ben-Mansour, R., Habib, M.A., Bamidele, O.E., Basha, M., Qasem, N.A.A., Peedikakkal, A., Laoui, T., Ali, M., 2016. Carbon capture by physical adsorption: Materials, experimental investigations and numerical modeling and simulations - A review. Appl. Energy 161, 225-255. https://doi.org/10.1016/j.apenergy.2015.10.011

Biloe, S., Goetz, V., Mauran, S., 2001. Characterization of adsorbent composite blocks for methane storage. Carbon 39, 1653-1662. https://doi.org/10.1016/S0008-6223(00)00288-8

Blankenship Ii, T.S., Balahmar, N., Mokaya, R., 2017. Oxygen-rich microporous carbons with exceptional hydrogen storage capacity. Nat. Commun. 8, 1545. https://doi.org/10.1038/s41467-017-01633-x

Bleda-Martínez, M.J., Pérez, J.M., Linares-Solano, A., Morallón, E., Cazorla-Amorós, D., 2008. Effect of surface chemistry on electrochemical storage of hydrogen in porous carbon materials. Carbon 46, 1053-1059. https://doi.org/10.1016/j.carbon.2008.03.016

Boyjoo, Y., Cheng, Y., Zhong, H., Tian, H., Pan, J., Pareek, V.K., Jiang, S.P., Lamonier, J.F., Jaroniec, M., Liu, J., 2017. From waste Coca Cola ${ }^{\circledR}$ to activated carbons with impressive capabilities for CO2adsorption and supercapacitors. Carbon 116, 490-499. https://doi.org/10.1016/j.carbon.2017.02.030

Builes, S., Roussel, T., Ghimbeu, C.M., Parmentier, J., Gadiou, R., Vix-Guterl, C., Vega, L.F., 2011. Microporous carbon adsorbents with high $\mathrm{CO} 2$ capacities for industrial applications. Phys. Chem. Chem. Phys. 13, 16063-16070. https://doi.org/10.1039/C1CP21673B 
Burchell, T., Rogers, M., 2000. Low Pressure Storage of Natural Gas for Vehicular Applications, SAE Tech. Pap. https://doi.org/10.4271/2000

Buss, E., 1995. Gravimetric measurement of binary gas adsorption equilibria of methane-carbon dioxide mixtures on activated carbon. Gas Sep. Purif. 9, 189-197. https://doi.org/10.1016/0950-4214(95)98226-B

Byamba-Ochir, N., Shim, W.G., Balathanigaimani, M.S., Moon, H., 2017. High density Mongolian anthracite based porous carbon monoliths for methane storage by adsorption. Appl. Energy 190, 257-265. https://doi.org/10.1016/j.apenergy.2016.12.124

Caglayan, B.S., Aksoylu, A.E., 2013. CO2adsorption on chemically modified activated carbon. J. Hazard. Mater. 252-253, 19-28. https://doi.org/10.1016/j.jhazmat.2013.02.028

Casco, M.E., Martínez-Escandell, M., Gadea-Ramos, E., Kaneko, K., Silvestre-Albero, J., RodríguezReinoso, F., 2015a. High-pressure methane storage in porous materials: Are carbon materials in the pole position? Chem. Mater. 27, 959-964. https://doi.org/10.1021/cm5042524

Casco, M.E., Martínez-Escandell, M., Gadea-Ramos, E., Kaneko, K., Silvestre-Albero, J., RodríguezReinoso, F., 2015b. High-pressure methane storage in porous materials: Are carbon materials in the pole position? Chem. Mater. 27, 959-964. https://doi.org/10.1021/cm5042524

Cavenati, S., Grande, C.A., Rodrigues, A.E., 2004. Adsorption Equilibrium of Methane, Carbon Dioxide, and Nitrogen on Zeolite 13X at High Pressures. J. Chem. Eng. Data 49, 1095-1101. https://doi.org/10.1021/je0498917

Chahine, R., Bose, T.K., 1994. Low-pressure adsorption storage of hydrogen. Int. J. Hydrog. Energy 19, 161-164. https://doi.org/10.1016/0360-3199(94)90121-X

Chen, C., Ahn, W.S., 2014. CO2 adsorption on LTA zeolites: Effect of mesoporosity. Appl. Surf. Sci. 311, 107-109. https://doi.org/10.1016/j.apsusc.2014.04.218

Choi, P.-S., Jeong, J.-M., Choi, Y.-K., Kim, M.-S., Shin, G.-J., Park, S.-J., 2016. A review: methane capture by nanoporous carbon materials for automobiles. Carbon Lett. 17, 18-28. https://doi.org/10.5714/CL.2016.17.1.018

Choi, Y.-K., Park, S.-J., 2015. Preparation and characterization of sucrose-based microporous carbons for increasing hydrogen storage. J. Ind. Eng. Chem. 28, 32-36.

Core Writing Team, Pachauri, R.K., Meyer, L.A., 2014. Climate Change 2014 Synthesis Report. Contribution of Working Groups I, II and III to the Fifth Assessment Report of the Intergovernmental Panel on Climate Change.

Cracknell, R.F., Gordon, P., Gubbins, K.E., 1993. Influence of pore geometry on the design of microporous materials for methane storage. J. Phys. Chem. 97, 494-499. https://doi.org/10.1021/j100104a036

Deng, S., Wei, H., Chen, T., Wang, B., Huang, J., Yu, G., 2014. Superior CO2adsorption on pine nut shell-derived activated carbons and the effective micropores at different temperatures. Chem. Eng. J. 253, 46-54. https://doi.org/10.1016/j.cej.2014.04.115

Dillon AC, Parilla PA, Zhao Y, Kim YH, Gennett T, Curtis C, Heben MJ, Blackburn JL, Gilbert KEH, Alleman JL, Jones KM, Zhang SB, n.d. NREL activities in DOE Carbon-based Materials Center of Excellence.

Drage, T.C., Blackman, J.M., Pevida, C., Snape, C.E., 2009. Evaluation of Activated Carbon Adsorbents for CO 2 Capture in Gasification. Energy Fuels 23, 2790-2796. https://doi.org/10.1021/ef8010614

Durbin, D.J., Malardier-Jugroot, C., 2013. Review of hydrogen storage techniques for on board vehicle applications. Int. J. Hydrog. Energy 38, 14595-14617. https://doi.org/10.1016/j.ijhydene.2013.07.058

EEA, 2014. Trends and projections in Europe 2014, EEA Report 6/2014. https://doi.org/10.2800/93693

Encyclopedia Britannica, 2018. Air, Atmospheric Gas [WWW Document]. URL https://www.britannica.com/science/air 
Energy, U.S. Department of Energy: Washington, D., 2012. MOVE: Methane Oppurtuities for Vehicular Energy. Advanced Research Projects Agency [WWW Document]. URL http://arpae.energy.gov/?q=arpa-e- programs/move (accessed 5.5.18).

EPA, 2016. Inventory of U.S. Greenhouse Emissions and Sinks.

Feroldi, M., Neves, A.C., Borba, C.E., Alves, H.J., 2018. Methane storage in activated carbon at low pressure under different temperatures and flow rates of charge. J. Clean. Prod. 172, 921926. https://doi.org/10.1016/j.jclepro.2017.10.247

García Blanco, A.A., Vallone, A.F., Korili, S.A., Gil, A., Sapag, K., 2016. A comparative study of several microporous materials to store methane by adsorption. Microporous Mesoporous Mater. 224, 323-331. https://doi.org/10.1016/j.micromeso.2016.01.002

Georgakis, M., Stavropoulos, G., Sakellaropoulos, G.P., 2007. Molecular dynamics study of hydrogen adsorption in carbonaceous microporous materials and the effect of oxygen functional groups. Int. J. Hydrog. Energy 32, 1999-2004. https://doi.org/10.1016/j.ijhydene.2006.08.040

Global CCS Institue, 2011. Accelerating the Uptake of CCS: Industrial Use of Captured Carbon Dioxide.

González-García, P., 2018. Activated carbon from lignocellulosics precursors: A review of the synthesis methods, characterization techniques and applications. Renew. Sustain. Energy Rev. 82, 1393-1414. https://doi.org/10.1016/j.rser.2017.04.117

Gui, M.M., Yap, Y.X., Chai, S.P., Mohamed, A.R., 2013. Multi-walled carbon nanotubes modified with (3-aminopropyl)triethoxysilane for effective carbon dioxide adsorption. Int. J. Greenh. Gas Control 14, 65-73. https://doi.org/10.1016/j.ijggc.2013.01.004

Hao, W., Björkman, E., Lilliestråle, M., Hedin, N., 2013. Activated carbons prepared from hydrothermally carbonized waste biomass used as adsorbents for CO2. Appl. Energy 112, 526-532. https://doi.org/10.1016/j.apenergy.2013.02.028

Heo, Y.-J., Park, S.-J., 2015. Synthesis of activated carbon derived from rice husks for improving hydrogen storage capacity. J. Ind. Eng. Chem. 31, 330-334. https://doi.org/10.1016/j.jiec.2015.07.006

Hosseini, S., Bayesti, I., Marahel, E., Eghbali Babadi, F., Chuah Abdullah, L., Choong, T.S.Y., 2015. Adsorption of carbon dioxide using activated carbon impregnated with $\mathrm{Cu}$ promoted by zinc. J. Taiwan Inst. Chem. Eng. 52, 109-117. https://doi.org/10.1016/j.jtice.2015.02.015

Huang, C.-C., Chen, H.-M., Chen, C.-H., Huang, J.-C., 2010. Effect of surface oxides on hydrogen storage of activated carbon. Sep. Purif. Technol. 3, 291-295. https://doi.org/10.1016/j.seppur.2009.10.009

Intergovernmental Panel on Climate Change (IPCC), 2007. Human and Natural Drivers of Climate Change [WWW Document]. URL https://www.ipcc.ch/publications_and_data/ar4/wg1/en/spmsspm-human-and.html (accessed 3.25.18).

Intergovernmental Panel on Climate Change (IPCC), 2005. Carbon Dioxide Capture and Storage, Cambridge University Press.

International Energy Agency, 2017. CO2 emissions from fuel combustion. Highlights.

Kacem, M., Pellerano, M., Delebarre, A., 2015. Pressure swing adsorption for $\mathrm{CO}<\mathrm{inf}>2</ \mathrm{inf}>/ \mathrm{N}<\mathrm{inf}>2</$ inf $>$ and $\mathrm{CO}<\mathrm{inf}>2</ \mathrm{inf}>/ \mathrm{CH}<\mathrm{inf}>4</$ inf $>$ separation: Comparison between activated carbons and zeolites performances. Fuel Process. Technol. 138, 271-283. https://doi.org/10.1016/j.fuproc.2015.04.032

Kumar, K.V., Preuss, K., Titirici, M.M., Rodríguez-Reinoso, F., 2017a. Nanoporous Materials for the Onboard Storage of Natural Gas. Chem. Rev. 117, 1796-1825. https://doi.org/10.1021/acs.chemrev.6b00505

Kumar, K.V., Preuss, K., Titirici, M.M., Rodríguez-Reinoso, F., 2017b. Nanoporous Materials for the Onboard Storage of Natural Gas. Chem. Rev. 117, 1796-1825. https://doi.org/10.1021/acs.chemrev.6b00505 
Lee, J.W., Kang, H.C., Shim, W.G., Kim, C., Moon, H., 2006. Methane adsorption on multi-walled carbon nanotube at $(303.15,313.15$, and 323.15) K. J. Chem. Eng. Data 51, 963-967. https://doi.org/10.1021/je050467v

Lee, S.Y., Park, S.J., 2015. A review on solid adsorbents for carbon dioxide capture. J. Ind. Eng. Chem. 23, 1-11. https://doi.org/10.1016/j.jiec.2014.09.001

Lee, Z.H., Lee, K.T., Bhatia, S., Mohamed, A.R., 2012. Post-combustion carbon dioxide capture: Evolution towards utilization of nanomaterials. Renew. Sustain. Energy Rev. 16, 2599-2609. https://doi.org/10.1016/j.rser.2012.01.077

Li, G., Li, J., Tan, W., Jin, H., Yang, H., Peng, J., Barrow, C.J., Yang, M., Wang, H., Yang, W., 2016. Preparation and characterization of the hydrogen storage activated carbon from coffee shell by microwave irradiation and $\mathrm{KOH}$ activation. Int. Biodeterior. Biodegrad., Challenges in Environmental Science and Engieering - 2015 113, 386-390. https://doi.org/10.1016/j.ibiod.2016.05.003

Li, J.R., Ma, Y., McCarthy, M.C., Sculley, J., Yu, J., Jeong, H.K., Balbuena, P.B., Zhou, H.C., 2011. Carbon dioxide capture-related gas adsorption and separation in metal-organic frameworks. Coord. Chem. Rev. 255, 1791-1823. https://doi.org/10.1016/j.ccr.2011.02.012

Liu, J., Zou, R., Zhao, Y., 2016. Recent developments in porous materials for H2and CH4storage. Tetrahedron Lett. 57, 4873-4881. https://doi.org/10.1016/j.tetlet.2016.09.085

Liu, X., Zhang, C., Geng, Z., Cai, M., 2014. High-pressure hydrogen storage and optimizing fabrication of corncob-derived activated carbon. Microporous Mesoporous Mater. 194, 60-65. https://doi.org/10.1016/j.micromeso.2014.04.005

Li, Y., Li, D., Rao, Y., Zhao, X., Wu, M., 2016. Superior $\mathrm{CO}<\inf >2</$ inf $>, \mathrm{CH}<\mathrm{inf}>4</$ inf $>$, and $\mathrm{H}<$ inf $>2</$ inf $>$ uptakes over ultrahigh-surface-area carbon spheres prepared from sustainable biomass-derived char by CO<inf $>2</$ inf $>$ activation. Carbon 105, 454-462. https://doi.org/10.1016/j.carbon.2016.04.036

Llewellyn, P.L., Bourrelly, S., Serre, C., Vimont, A., Daturi, M., Hamon, L., Weireld, G. De, Chang, J., Hong, D., Hwang, Y.K., Jhung, S.H., 2008. High Uptakes of $\mathrm{CO} 2$ and $\mathrm{CH} 4$ in Mesoporous MetalsOrganic Frameworks MIL-100 and MIL-101. Langmuir 7245-7250. https://doi.org/10.1021/la800227x

Llorens, J., Pera-Titus, M., 2009. Influence of surface heterogeneity on hydrogen adsorption on activated carbons. Colloids Surf. Physicochem. Eng. Asp. 350, 63-72. https://doi.org/10.1016/j.colsurfa.2009.08.035

Lozano-Castelló, D., Cazorla-Amorós, D., Linares-Solano, A., Quinn, D.F., 2002. Influence of pore size distribution on methane storage at relatively low pressure: Preparation of activated carbon with optimum pore size. Carbon 40, 989-1002. https://doi.org/10.1016/S00086223(01)00235-4

Masika, E., Mokaya, R., 2013. Preparation of ultrahigh surface area porous carbons templated using zeolite 13X for enhanced hydrogen storage. Prog. Nat. Sci. Mater. Int. 23, 308-316. https://doi.org/10.1016/j.pnsc.2013.04.007

Masika, E., Mokaya, R., 2012. Hydrogen Storage in High Surface Area Carbons with Identical Surface Areas but Different Pore Sizes: Direct Demonstration of the Effects of Pore Size. J. Phys. Chem. C 116, 25734-25740. https://doi.org/10.1021/jp3100365

Ma, S., Sun, D., Simmons, J.M., Collier, C.D., Yuan, D., Zhou, H.C., 2008. Metal-organic framework from an anthracene derivative containing nanoscopic cages exhibiting high methane uptake. J. Am. Chem. Soc. 130, 1012-1016. https://doi.org/10.1021/ja0771639

Matranga, K.R., Myers, A.L., Glandt, E.D., 1992. Storage of Natural-Gas By Adsorption on Activated Carbon. Chem. Eng. Sci. 47, 1569-1579. https://doi.org/10.1016/0009-2509(92)85005-v

Md Arshad, S.H., Ngadi, N., Aziz, A.A., Amin, N.S., Jusoh, M., Wong, S., 2016. Preparation of activated carbon from empty fruit bunch for hydrogen storage. J. Energy Storage 8, 257-261. https://doi.org/10.1016/j.est.2016.10.001 
Meng, L.Y., Park, S.J., 2014. One-pot synthetic method to prepare highly N-doped nanoporous carbons for CO2adsorption. Mater. Chem. Phys. 143, 1158-1163.

https://doi.org/10.1016/j.matchemphys.2013.11.016

Menon, V.C., Komarneni, S., 1998. Porous adsorbents for vehicular natural gas storage: a review. J. Porous Mater. 5, 43-58. https://doi.org/10.1023/A:1009673830619

Mozammel, H.M., Masahiro, O., Bhattacharya, S.C., 2002. Activated charcoal from coconut shell using $\mathrm{ZnCl} 2$ activation. Biomass Bioenergy 22, 397-400. https://doi.org/10.1016/S09619534(02)00015-6

Munusamy, K., Somani, R.S., Bajaj, H.C., 2015. Breakthrough adsorption studies of mixed gases on mango (Mangifera indicaL.) seed shell derived activated carbon extrudes. J. Environ. Chem. Eng. 3, 2750-2759. https://doi.org/10.1016/j.jece.2015.05.010

NASA, 2018. Carbon Dioxide 2018 [WWW Document]. URL https://climate.nasa.gov/vitalsigns/carbon-dioxide/ (accessed 3.25.18).

National Center for Biotechnology Information, n.d. PubChem Compound Database; CID=297 [WWW Document]. URL https://pubchem.ncbi.nlm.nih.gov/compound/297 (accessed 4.19.18).

NaturalGas.org, n.d. Natural Gas and the Environment [WWW Document]. URL http://naturalgas.org/environment/naturalgas/ (accessed 5.4.18).

Office of Energy Efficiency \& Renewable Energy, n.d. DOE Technical Targets for Onboard Hydrogen Storage for Light-Duty Vehicles [WWW Document]. URL https://www.energy.gov/eere/fuelcells/doe-technical-targets-onboard-hydrogen-storagelight-duty-vehicles

Oh, T.H., 2010. Carbon capture and storage potential in coal-fired plant in Malaysia - A review. Renew. Sustain. Energy Rev. 14, 2697-2709. https://doi.org/10.1016/j.rser.2010.06.003

Plaza, M.G., García, S., Rubiera, F., Pis, J.J., Pevida, C., 2010. Post-combustion CO2capture with a commercial activated carbon: Comparison of different regeneration strategies. Chem. Eng. J. 163, 41-47. https://doi.org/10.1016/j.cej.2010.07.030

Plaza, M.G., Pevida, C., Arias, B., Fermoso, J., Arenillas, A., Rubiera, F., Pis, J.J., 2008. Application of thermogravimetric analysis to the evaluation of aminated solid sorbents for CO2capture. J. Therm. Anal. Calorim. 92, 601-606. https://doi.org/10.1007/s10973-007-8493-x

Policicchio, A., MacCallini, E., Agostino, R.G., Ciuchi, F., Aloise, A., Giordano, G., 2013. Higher methane storage at low pressure and room temperature in new easily scalable large-scale production activated carbon for static and vehicular applications. Fuel 104, 813-821. https://doi.org/10.1016/j.fuel.2012.07.035

Presser, V., McDonough, J., Yeon, S.-H., Gogotsi, Y., 2011. Effect of pore size on carbon dioxide sorption by carbide derived carbon. Energy Environ. Sci. 4, 3059. https://doi.org/10.1039/c1ee01176f

Ramesh, T., Rajalakshmi, N., Dhathathreyan, K.S., 2017. Synthesis and characterization of activated carbon from jute fibers for hydrogen storage. Renew. Energy Environ. Sustain. 2, 4. https://doi.org/10.1051/rees/2017001

Ramesh, T., Rajalakshmi, N., Dhathathreyan, K.S., 2015. Activated carbons derived from tamarind seeds for hydrogen storage. J. Energy Storage 4, 89-95.

https://doi.org/10.1016/j.est.2015.09.005

Ren, J., Musyoka, N.M., Langmi, H.W., Mathe, M., Liao, S., 2017. Current research trends and perspectives on materials-based hydrogen storage solutions: A critical review. Int. J. Hydrog. Energy 42, 289-311. https://doi.org/10.1016/j.ijhydene.2016.11.195

Ruiz, B., Ferrera-Lorenzo, N., Fuente, E., 2017. Valorisation of lignocellulosic wastes from the candied chestnut industry. Sustainable activated carbons for environmental applications. J. Environ. Chem. Eng. 5, 1504-1515. https://doi.org/10.1016/j.jece.2017.02.028

Schaefer, S., Fierro, V., Izquierdo, M.T., Celzard, A., 2016. Assessment of hydrogen storage in activated carbons produced from hydrothermally treated organic materials. Int. J. Hydrog. Energy 41, 12146-12156. https://doi.org/10.1016/j.ijhydene.2016.05.086 
Schimmel, H.G., Kearley, G.J., Nijkamp, M.G., Visser, C.T., Jong, K.P. de, Mulder, F.M., 2003. Hydrogen Adsorption in Carbon Nanostructures: Comparison of Nanotubes, Fibers, and Coals. Chem. Eur. J. 9, 4764-4770. https://doi.org/10.1002/chem.200304845

Seema, H., Kemp, K.C., Le, N.H., Park, S.W., Chandra, V., Lee, J.W., Kim, K.S., 2014. Highly selective CO2capture by S-doped microporous carbon materials. Carbon 66, 320-326. https://doi.org/10.1016/j.carbon.2013.09.006

Serafin, J., Narkiewicz, U., Morawski, A.W., Wróbel, R.J., Michalkiewicz, B., 2017. Highly microporous activated carbons from biomass for $\mathrm{CO}$ capture and effective micropores at different conditions. J. CO2 Util. 18, 73-79. https://doi.org/10.1016/j.jcou.2017.01.006

Sethia, G., Sayari, A., 2016. Activated carbon with optimum pore size distribution for hydrogen storage. Carbon 99, 289-294. https://doi.org/10.1016/j.carbon.2015.12.032

Sevilla, M., Falco, C., Titirici, M.-M., Fuertes, A.B., 2012. High-performance CO2 sorbents from algae. RSC Adv. 2, 12792. https://doi.org/10.1039/c2ra22552b

Shafeeyan, M.S., Daud, W.M.A.W., Houshmand, A., Arami-Niya, A., 2011. Ammonia modification of activated carbon to enhance carbon dioxide adsorption: Effect of pre-oxidation. Appl. Surf. Sci. 257, 3936-3942. https://doi.org/10.1016/j.apsusc.2010.11.127

Singh, G., Lakhi, K.S., Kim, I.Y., Kim, S., Srivastava, P., Naidu, R., Vinu, A., 2017. Highly Efficient Method for the Synthesis of Activated Mesoporous Biocarbons with Extremely High Surface Area for High-Pressure $\mathrm{CO}_{2}$ Adsorption. ACS Appl. Mater. Interfaces 9, 29782-29793. https://doi.org/10.1021/acsami.7b08797

Somy, A., Mehrnia, M.R., Amrei, H.D., Ghanizadeh, A., Safari, M., 2009. Adsorption of carbon dioxide using impregnated activated carbon promoted by Zinc. Int. J. Greenh. Gas Control 3, 249254. https://doi.org/10.1016/j.ijggc.2008.10.003

Song, T., Liao, J.M., Xiao, J., Shen, L.H., 2015. Effect of micropore and mesopore structure on CO2adsorption by activated carbons from biomass. Xinxing Tan CailiaoNew Carbon Mater. 30, 156-166. https://doi.org/10.1016/S1872-5805(15)60181-0

Son, S.-J., Choi, J.-S., Choo, K.-Y., Song, S.-D., Vijayalakshmi, S., Kim, T.-H., 2005. Development of carbon dioxide adsorbents using carbon materials prepared from coconut shell. Korean J. Chem. Eng. 22, 291-297. https://doi.org/10.1007/BF02701500

Takagi, H., Hatori, H., Yamada, Y., Matsuo, S., Shiraishi, M., 2004. Hydrogen adsorption properties of activated carbons with modified surfaces. J. Alloys Compd. 385, 257-263. https://doi.org/10.1016/j.jallcom.2004.03.139

Tellez-Juarez, M.C., Fierro, V., Zhao, W., Fernandez-Huerta, N., Izquierdo, M.T., Reguera, E., Celzard, A., 2014. Hydrogen storage in activated carbons produced from coals of different ranks: Effect of oxygen content. Int. J. Hydrog. Energy 39, 4996-5002. https://doi.org/10.1016/j.ijhydene.2014.01.071

Texier-Mandoki, N., Dentzer, J., Piquero, T., Saadallah, S., David, P., Vix-Guterl, C., 2004. Hydrogen storage in activated carbon materials: Role of the nanoporous texture. Carbon 42, 27442747. https://doi.org/10.1016/j.carbon.2004.05.018

Tiwari, D., Bhunia, H., Bajpai, P.K., 2017. Synthesis of nitrogen enriched porous carbons from urea formaldehyde resin and their carbon dioxide adsorption capacity. J. CO2 Util. 21, 302-313. https://doi.org/10.1016/j.jcou.2017.08.002

United States Environmental Protection Agency (EPA), n.d. Overview of Greenhouse Gases 2016.

V, F., W, Z., Mt, I., E, A., A, C., 2010. Adsorption and compression contributions to hydrogen storage in activated anthracites. Int. J. Hydrog. Energy 35, 9038-9045.

Wang, H., Gao, Q., Hu, J., 2009. High Hydrogen Storage Capacity of Porous Carbons Prepared by Using Activated Carbon. J. Am. Chem. Soc. 131, 7016-7022. https://doi.org/10.1021/ja8083225

Wang, J., Kaskel, S., 2012. KOH activation of carbon-based materials for energy storage. J. Mater. Chem. 22, 23710. https://doi.org/10.1039/c2jm34066f

Wang, J., Senkovska, I., Kaskel, S., Liu, Q., 2014. Chemically activated fungi-based porous carbons for hydrogen storage. Carbon 75, 372-380. https://doi.org/10.1016/j.carbon.2014.04.016 
Wang, Z., Sun, L., Xu, F., Zhou, H., Peng, X., Sun, D., Wang, J., Du, Y., 2016. Nitrogen-doped porous carbons with high performance for hydrogen storage. Int. J. Hydrog. Energy 41, 8489-8497. https://doi.org/10.1016/j.ijhydene.2016.03.023

Wróbel-Iwaniec, I., Díez, N., Gryglewicz, G., 2015. Chitosan-based highly activated carbons for hydrogen storage. Int. J. Hydrog. Energy 40, 5788-5796. https://doi.org/10.1016/j.ijhydene.2015.03.034

Xiao, Y., Dong, H., Long, C., Zheng, M., Lei, B., Zhang, H., Liu, Y., 2014. Melaleuca bark based porous carbons for hydrogen storage. Int. J. Hydrog. Energy 39, 11661-11667. https://doi.org/10.1016/j.ijhydene.2014.05.134

Yamasaki, A., 2003. An Overview of CO2 Mitigation Options for Global Warming-Emphasizing CO2 Sequestration Options. J. Chem. Eng. Jpn. 36, 361-375.

Yang, R., Liu, G., Li, M., Zhang, J., Hao, X., 2012. Preparation and N2, CO2 and H2 adsorption of super activated carbon derived from biomass source hemp (Cannabis sativa L.) stem. Microporous Mesoporous Mater. 158, 108-116. https://doi.org/10.1016/j.micromeso.2012.03.004

Yaumi, A.L., Bakar, M.Z.A., Hameed, B.H., 2018. Melamine-nitrogenated mesoporous activated carbon derived from rice husk for carbon dioxide adsorption in fixed-bed. Energy Accepted M. https://doi.org/10.1016/j.energy.2018.04.183

Yin, G., Liu, Z., Liu, Q., Wu, W., 2013. The role of different properties of activated carbon in CO2adsorption. Chem. Eng. J. 230, 133-140. https://doi.org/10.1016/j.cej.2013.06.085

Yong, Z.O.U., Mata, V.G., 2001. Adsorption of Carbon Dioxide on Chemically Modified High Surface Area Carbon-Based Adsorbents at High Temperature. Adsorption 41-50. https://doi.org/10.1023/A:1011220900415

Zhang, J., Gao, J., Chen, Y., Hao, X., Jin, X., 2017. Characterization, preparation, and reaction mechanism of hemp stem based activated carbon. Results Phys. 7, 1628-1633. https://doi.org/10.1016/j.rinp.2017.04.028

Zhao, X.B., Xiao, B., Fletcher, A.J., Thomas, K.M., 2005. Hydrogen Adsorption on Functionalized Nanoporous Activated Carbons. J. Phys. Chem. B 109, 8880-8888. https://doi.org/10.1021/jp050080z

Zhou, W., Wu, H., Hartman, M.R., Yildirim, T., 2007. Hydrogen and methane adsorption in metalorganic frameworks: A high-pressure volumetric study. J. Phys. Chem. C 111, 16131-16137. https://doi.org/10.1021/jp074889i 